\title{
What to Wear: The Filtration Performance of Alternative Materials Used to Construct Do-It-Yourself Masks
}

Special Issue:

Special Issue on COVID-19 Aerosol Drivers, Impacts and Mitigation $(\mathrm{XVI})$

\author{
Jessica A. Mirrielees ${ }^{1}$, Bo Chen ${ }^{1}$, Michael R. Moreno ${ }^{2}$, Sarah D. Brooks ${ }^{1^{*}}$ \\ ${ }^{1}$ Department of Atmospheric Sciences, Texas A\&M University, College Station, TX 77843, USA \\ ${ }^{2}$ Department of Mechanical Engineering, Texas A\&M University, College Station, TX 77840, USA
}

\begin{abstract}
The COVID-19 pandemic has shown that much of the world, including the United States, is illprepared for the material demands of a global crisis. In response to this shortage of Personal Protective Equipment (PPE), we have conducted filtration efficiency and pressure drop testing of a range of common materials used for constructing do-it-yourself masks, including an allergen filter, a vacuum bag, a heavy-duty tool wipe, and a standard cotton bandana, as well as a standard 3-ply surgical mask, a medical drape and an industrially available composite filter material. Sizeresolved percent penetration of each material by particles with diameters ranging from 25 to $500 \mathrm{~nm}$ was measured at three face velocities $\left(0.72 \mathrm{~cm} \mathrm{~s}^{-1}, 4.30 \mathrm{~cm} \mathrm{~s}^{-1}, 13.0 \mathrm{~cm} \mathrm{~s}^{-1}\right)$. The allergen filter performed best, only allowing the penetration of $5 \% \pm 3 \%$ of the $300 \mathrm{~nm}$ particles through the material at a face velocity of $13.0 \mathrm{~cm} \mathrm{~s}^{-1}$, comparable to human breathing during heavy physical work. In comparison, the surgical mask and the cotton bandana allowed $39 \pm 1 \%$ and $51 \% \pm 1 \%$ of the $300 \mathrm{~nm}$ particles to pass through at the same face velocity, respectively. According to the calculated filter quality, the best choices for mask construction are the allergen filter, industrial composite filter, and the vacuum bag. Structure and morphology of the materials were characterized by scanning electron microscopy (SEM), image analysis, and thickness measurements to investigate physical characteristics which improve filtration. This study shows that certain household and commercially available materials and combinations can be used in the construction of highly effective face masks.
\end{abstract}

Keywords: Cloth mask, Filter quality, COVID-19, Airborne transmission

\section{INTRODUCTION}

A cumulative total exceeding 29 million cases of COVID-19 were confirmed in the United States by the middle of March 2021, and over 530,000 of these infected individuals have died (WHO, 2021). COVID-19 is caused by a novel coronavirus, SARS-CoV-2. In order to limit the spread of this disease, the World Health Organization (WHO) and the United States Center for Disease Control (CDC) have recommended the usage of face masks when in public (NCIRD, 2020). Unfortunately, the average citizen is hard-pressed to find adequate masks, or to decide which materials will be the most effective in protecting them from the virus. Conflicting statements about the efficacy of cloth face coverings from various organizations and levels of government have led to confusion among the general public about the benefits of wearing these alternative protective items and the relative performance of various materials available for mask construction.

The diameter of SARS-CoV-2 has a mean value of approximately $100 \mathrm{~nm}$ and a range of 60 to $140 \mathrm{~nm}$ (Zhu et al., 2020). While respiratory infections may be transmitted through airborne particles, droplets, and direct contact, airborne particles with diameters below $5000 \mathrm{~nm}$ are considered the primary route for the transmission (Wells, 1955). While the relative significance of various routes of its transmission are unknown (Han et al., 2020; Wang and Du, 2020), there is evidence 
that SARS-CoV-2 is transmitted via by both airborne droplets and aerosols with diameters $<5000 \mathrm{~nm}$ (Allen and Marr, 2020). In one report (Morawska et al., 2009), the submicron diameter aerosols $(800 \pm 80 \mathrm{~nm}$ ) accounted for $69-73 \%$ of particles generated by normal speech, $85-95 \%$ of particles generated by whispering, $86 \%$ of particles generated by breathing at a natural pace, and $84 \%$ of particles generated by coughing. Another study found that a significant fraction of particles generated by coughing have diameters in the 350-1000 $\mathrm{nm}$ range (Lindsley et al., 2010). Stadnytskyi 2020 determined that the initial diameter range of droplets generated through loud speech was 12,000 to $21,000 \mathrm{~nm}$, though these droplets quickly dehydrate in the air, resulting in an average dehydrated droplet diameter of approximately $4000 \mathrm{~nm}$. Further, one minute of loud speech from an individual infected with SARS-CoV-2 may generate at least 1000 virus-containing aerosols or droplets, which remain airborne for over eight minutes (Stadnytskyi et al., 2020).

A study of two hospitals in Wuhan found that SARS-CoV-2 is present in both submicron (250$1000 \mathrm{~nm}$ ) and supermicron (> $1000 \mathrm{~nm}$ ) aerosol (Liu et al., 2020). Submicron particles are capable of remaining airborne for some time due to their low settling velocities (Wang and Du, 2020). For example, an aerosol particle with a diameter of $100 \mathrm{~nm}$ will take over 83 hours to fall $1 \mathrm{~m}$ through the air in the absence of other forces, while a $300 \mathrm{~nm}$ droplet will require approximately half as much time, 43 hours, to fall the same distance (Wells, 1934). It should be noted that these calculations do not take particle evaporation into account, which is influenced by the composition of the droplet as well as ambient temperature and humidity. It has been observed that SARS-CoV-2 present in submicron aerosol particles can remain viable, and therefore infectious, for periods longer than three hours (van Doremalen et al., 2020). One study found that the virus remains infective even when aged in aerosol form for over twelve hours, and thus aerosol transmission may be an important pathway for transport of SARS-CoV-2 (Fears et al., 2020). An additional complication to the problem of respiratory protection is the observation that viral RNA from SARS-CoV-2 may be shed through sputum after an infected individual's symptoms are alleviated. Post-symptomatic and asymptomatic individuals are therefore capable of producing submicron, airborne, virus-laden aerosol particles (Wölfel et al., 2020).

Classical filtration theory describes the manner in which the characteristics of filters, including fiber diameter, packing density, and filter thickness, as well as characteristics of the challenge aerosol such as particle diameter, shape, electrical charge, and the flow rate of the airstream passing through the filter influence filter efficiency (Stevens and Moyer, 1989). The particle diameter for which maximum penetration is observed for a filter material at a specific face velocity is known as the most penetrating particle size, or MPPS. Face velocity is defined as the linear velocity $\left(\mathrm{cm} \mathrm{s}^{-1}\right)$ of air or particles through a medium. Face velocity is calculated by dividing the flow rate through the medium (here, a filter) by the surface area through which it passes (here, the filter material) (Rengasamy et al., 2010).

According to classical filtration theory, particles with smaller diameters are more effectively collected through Brownian diffusion, and particles with larger diameters are more effectively collected through impaction and interception (Alderman et al., 2008; Raynor et al., 2011). It follows that the estimated MPPS for airborne particles is approximately 100-300 nm (intermediate diameters) for passage through fibrous filters. Another consideration is that, as face velocity increases, the ability of aerosol particles to penetrate through the material increases (Stevens and Moyer, 1989; Eninger et al., 2008b) and the MPPS decreases (Eninger et al., 2008a; Huang et al., 2013). Face velocities that occur during inhalation and exhalation differ between individuals, and for the same individual during different activities (Anderson et al., 2006; Yuasa et al., 2015). Velocities consistent with breathing during moderate or strenuous activity may result in the decrease of MPPS to $<100 \mathrm{~nm}$ (Eninger et al., 2008a).

It is also necessary to assess the "breathability" of the material used for face mask construction, determined by the measured drop in pressure across the filter material. A filter that adequately attenuates particle concentration for a face velocity relevant to inhalation and exhalation is of little use if it provides such a high resistance to flow that the wearer must effectively breathe around the mask, rather than through it. This resistance to flow is quantified through the measurement of the pressure drop across the mask material.

The performance of a filter material can be assessed through a metric, filter quality, which takes both percent penetration and pressure drop into account. Filter quality, $q_{f}$, is calculated using Eq. (1): 
$q_{f}=\frac{\ln \left(\frac{100}{C}\right)}{\Delta p}$

where $C$ is the percent of particle concentration that penetrates the filter material and $\Delta p$ is the drop in pressure across the filter material (Brown, 1993). Comparisons of filter quality are considered more informative than comparisons of particle penetration alone since both concentration and pressure drop are taken into account. However, there are caveats in using filter quality to assess mask performance. Filter quality depends, in part, on the pressure drop across the filter material. This pressure drop tends to increase as face velocity increases. Face velocity will depend on dimensions of an individual mask, which can easily vary as much as $100 \%$ from one mask design to the next. Even when the mask dimensions are known, true face velocity is likely to be highest near the mouth and nose, and lower elsewhere on the mask, and this is not taken into account in filter quality calculations. In addition, filter quality does not account for how well a mask fits on one's face, or leakage which can occur around the edges of a mask. The importance of mask fit cannot be overstated as this is the only way to ensure that air inhaled is passing through the filter material versus going around it. In workplaces where masks are required, improper fit is considered an occupational safety hazard. Therefore, the Occupational Safety and Health Administration (OSHA), which establishes requirements for employers to follow to ensure employee safety, has delineated specific testing protocols for employers to ensure employees are wearing masks with an appropriate fit (OSHA, 2004).

According to the U.S. National Institute of Occupational Safety and Health (NIOSH) standard procedure NIOSH 42 CFR 84.180 , filter materials which block the penetration of at least $95 \%$ of the $300 \mathrm{~nm}$ diameter particles in an airstream are designated N95 materials. N95 respirators are considered the universal standard for PPE providing protection against particulate pollution. There is conflicting evidence on the ability of surgical masks to protect against inhalation of aerosol particles and droplets containing SARS-CoV-2. Some studies have found that surgical masks do not provide protection that is consistent with that of respiratory protection devices (Bałazy et al., 2006; Oberg and Brosseau, 2008; van der Sande et al., 2008), while another study found that use of surgical face masks significantly reduced the detection of SARS-CoV-2 RNA in aerosol particles, and somewhat reduced the detection of SARS-CoV-2 RNA in respiratory droplets (Leung et al., 2020).

A study on the efficacy of various materials in filtering the bacterium Bacillus atrophaeus (950$1250 \mathrm{~nm}$ diameter) and the virus, bacteriophage MS2 (diameter $23 \mathrm{~nm}$ ) found that three-layer surgical masks and vacuum cleaner bags allowed 4-6\% penetration of the bacteria and 10-14\% by the bacteriophage. The penetration observed for various cloth materials was $17-42 \%$ for the bacteria and $28-51 \%$ for the bacteriophage (Davies et al., 2013). These results agree with those in another study which showed that cloth masks made from tea towels provided roughly half the protection of three-layer surgical masks against the inhalation of particles with diameters 20$1000 \mathrm{~nm}$ (van der Sande et al., 2008).

A number of studies have investigated particle penetration through various cloth materials (Rengasamy et al., 2010; Davies et al., 2013; Jung et al., 2014; Shakya et al., 2017; Hao et al., 2020; Konda et al., 2020; Lustig et al., 2020; Zangmeister et al., 2020; Zhao et al., 2020). One study found that masks made from cloth exhibited penetration levels between $40 \%$ and $90 \%$ when challenged with $\mathrm{NaCl}$ aerosol particles with diameters in the 20-1000 nm range, and thus only provided marginal protection against inhaled infectious agents at face velocities of $5.5 \mathrm{~cm} \mathrm{~s}^{-1}$ and $16.5 \mathrm{~cm} \mathrm{~s}^{-1}$ (Rengasamy et al., 2010). These face velocities are somewhat higher than those consistent with light physical activity and the NIOSH N95 respirator certification test, respectively (Rengasamy et al., 2017). It should also be noted that little change in percent penetration was observed when the face velocity was increased from $5.5 \mathrm{~cm} \mathrm{~s}^{-1}$ to $16.5 \mathrm{~cm} \mathrm{~s}^{-1}$ in this study. A recently published evaluation of cloth face coverings made from household materials reported percent penetrations of $\geq 70 \%$ for various cotton, silk, nylon, and polyester fabrics using aerosol particles with $75 \pm 20 \mathrm{~nm}$ count median diameter and an aerosol flow rate typical of normal human breathing (face velocity unknown) (Zhao et al., 2020). Another study (Konda et al., 2020), which employed a face velocity of $9.89 \mathrm{~cm} \mathrm{~s}^{-1}$, found that the percent penetration for particles 
with diameters $10-1000 \mathrm{~nm}$ was relatively high (40-95\%) for one layer of 80 threads-per-inch cotton, but lower for one layer of 600 threads-per-inch cotton (5-35\%), one layer of chiffon (10$45 \%)$, and four layers of natural silk (5-20\%), and moderate for one layer of natural silk (30-60\%) and rather variable for one layer of cotton-polyester flannel (10-75\%).

The effect of adding additional layers to a single layer material has not been studied systematically. Konda et al. (2020) found that combinations of 600 threads-per-inch cotton with two layers of natural silk, two layers of chiffon, and one layer of cotton-polyester flannel decreased the percent penetration to $0-5 \%, 0-10 \%$, and $0-20 \%$ respectively. However, the study reports that the N95 respirator allowed up to $30 \%$ of the particles to penetrate the filter. This result is in disagreement with the stated performance of N95 material according to the standard testing procedure for N95 certification (NIOSH, 2019). In contrast to the results from Konda et al. (2020), another study found that increasing the number of layers of cotton and gauze handkerchiefs from one to four had negligible effect on percent penetration (consistently $>96 \%$ for both materials), though this did increase the pressure drop through the material, which in turns decreases filter quality (Jung et al., 2014). This study also demonstrated that fabric face masks made from woven cotton fabric do not perform as well as four-layer surgical masks (with penetration of $77 \% \pm 27 \%$ and $59 \% \pm$ $37 \%$, respectively). However, face masks made from nonwoven materials (materials which consist of bonded, layered fibers of varying length) outperformed the same four-layer surgical masks (penetration $45 \% \pm 9 \%$ ). To summarize the results of these studies, the best materials for mask construction consisted of combinations of materials (four layers of silk, or cotton layered with other fabrics). The poorest choices were single layers of cotton, gauze, t-shirts, and scarves.

An additional consideration in mask performance is the fit of various mask designs to the face. A study that compared three cloth face masks to N95 respirators found that one mask characterized by a conical or tetrahedral shape that included an exhalation valve performed similarly (5-20\% penetration) to an $\mathrm{N} 95$ respirator (5-15\% penetration) in removing 30-2500 nm polystyrene latex aerosol particles. The two other cloth masks, which were rectangular in shape and did not include exhalation valves, did not perform as well (15-85\% penetration for 30-2500 $\mathrm{nm}$ polystyrene latex aerosol particles) (Shakya et al., 2017).

Due to a shortage of suitable personal protective equipment during the pandemic, the CDC recommends making masks from cotton material, which most people will have at home in some form. A recent study has predicted that if as few as $50 \%$ of the population wears face masks when in public, and even if those face masks are only $50 \%$ effective, the rate at which SARS-CoV-2 spreads could be reduced by over $95 \%$ (Howard et al., 2020). Another study agrees that when $50 \%$ of the population wear masks, the spread is significantly reduced, and further reports that if $80 \%$ of the population wear masks, negligible transmission would occur (Yan et al., 2019). Therefore, face masks that provide protection against both the inhalation and exhalation of submicron aerosols and bare airborne viruses as well as supermicron droplets that may contain the virus are recommended. The goal of this study is to test a wide variety of commonly available candidate materials in order to determine which filter materials provide adequate protection across a range of particle diameters at representative inhalation flow rates observed for various levels of physical activity. Similar studies have been conducted on DIY masks. However, many have focused on various cloth masks (Rengasamy et al., 2010; Davies et al., 2013; Jung et al., 2014; Shakya et al., 2017; Konda et al., 2020; Zhao et al., 2020) in comparison to N95. Our study includes household, medical, and new industrial filter material options, and provided detailed structural and morphological characterizations, in an attempt to determine relevant structure-filtration relationships.

\section{METHODS}

\subsection{Filter Efficiency}

The filter efficiency of candidate materials for use in face masks and respirators was determined based on the percentage of particles sampled which passed through the material. Size-resolved measurements were conducted over the diameter range of 25-500 $\mathrm{nm}$. While the size range of virus-laden aerosols is uncertain, emphasis has been placed on two particle diameters, $100 \mathrm{~nm}$ and $300 \mathrm{~nm}$. The $300 \mathrm{~nm}$ particle diameter is significant because the standard NIOSH N95 certification specifically requires that $95 \%$ of the aerosol particles with a mass mean aerodynamic diameter 
of $300 \mathrm{~nm}$ in air be removed by a filter (NIOSH, 1995). However, $300 \mathrm{~nm}$ may not be the most penetrating particle size or the most important size to consider in the case of SARS-CoV-2. For comparison, $100 \mathrm{~nm}$ results are included since $100 \mathrm{~nm}$ is similar to the mean diameter of the SARS-CoV-2 virus (Zhu et al., 2020). In addition, pressure drop and filter quality are measured in this study. Finally, the biocompatibility of the chosen materials, though beyond the scope of our measurements, is discussed below.

An initial survey of the filtration efficiency of many common materials was conducted using the experimental set-up shown in Fig. 1(a). The selected materials included items widely available in the home, as well as common medical supplies. In addition, an industrial composite material (NxN Nano, Style NP097) which has been used in industry and recently made available to the public for use during the coronavirus pandemic was included. This material was specifically engineered for masks. It is a three-layer composite material of polypropylene Spunbond, thermoplastic polyurethane nanofiber and polyethylene terephthalate Spunlace. Finally, for comparison, a N95 respirator (3M, Model 8200/07023) was used as a standard.

To determine the percent penetration of particles through a potential mask material, a $5 \mathrm{~cm}$ diameter circle of the material was placed in a filter holder with a filtration area of $13.8 \mathrm{~cm}^{2}$ (Millipore In-Line Filter Holder, Catalogue Number XX4304700) and secured in place by an o-ring. Next, the filter holder was wrapped with parafilm in order to prevent leakage. In some cases, multiple layers of material were used (as reported in Table 1), to represent the way in which the given material would be worn or implemented in a DIY mask or respirator. For example, two layers

(a)

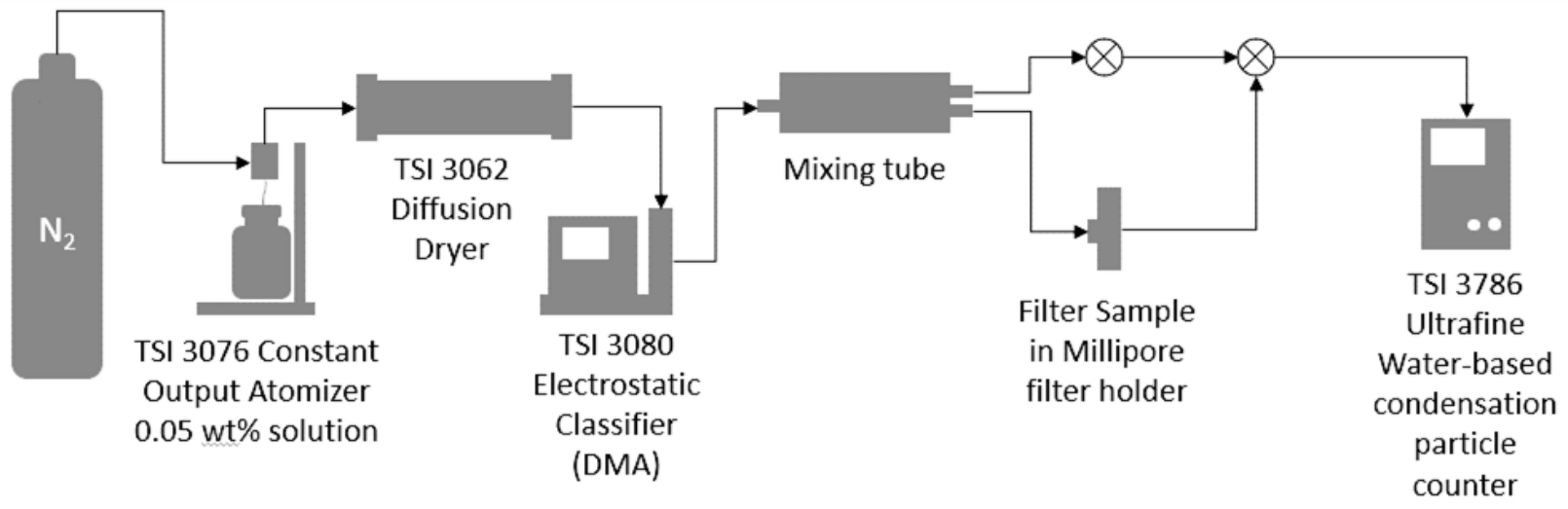

(b)

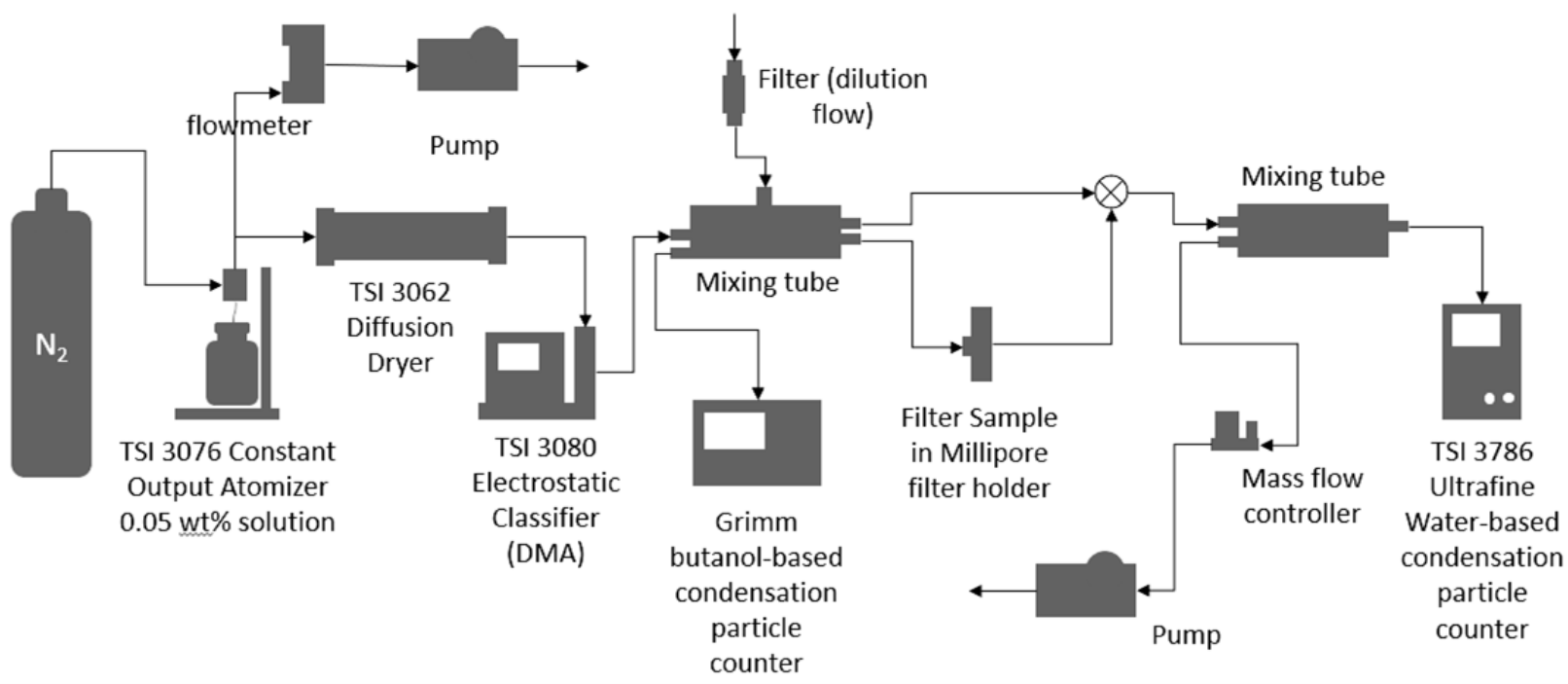

Fig. 1. Experimental setup for studying the effectiveness of filter materials to use for masks. (a) The instrument setup used in the initial survey is shown. The initial survey employed one condensation particle counter (TSI 3786), which was used to alternately measure the concentration of particles without and with the filter material in place. (b)The remaining experiments employed two condensation particle counters in order to simultaneously measure the concentration of aerosol particles with and without the filter material in line. 
Table 1. Percent penetration of aerosol particles at face velocity $=0.72 \mathrm{~cm} \mathrm{~s}^{-1}$.

\begin{tabular}{|c|c|c|c|}
\hline Filter Material & Manufacturer and Other Details & $\begin{array}{l}100 \mathrm{~nm} \text { Percent } \\
\text { Penetration }\end{array}$ & $\begin{array}{l}300 \mathrm{~nm} \text { Percent } \\
\text { Penetration }\end{array}$ \\
\hline $3 \mathrm{M}$ particle respirator $(\mathrm{N} 95)^{\mathrm{a}}$ & 3M Model 8200/07023 & $0 \pm 0$ & $0 \pm 0$ \\
\hline Allergen filter ${ }^{a}$ & $\begin{array}{l}\text { 3M Filtrete Premium Allergen and Ultrafine Particles, D } \\
\text { Filter Size, True HEPA, Model \#1150099, } 1 \text { layer }\end{array}$ & $0 \pm 0$ & $0 \pm 0$ \\
\hline Vacuum bag ${ }^{\text {a }}$ & Vacuum bag, Great Value “Eureka” style RR bag, 1 layer & $0 \pm 0$ & $0 \pm 0$ \\
\hline Surgical mask ${ }^{a}$ & Unigard FluidBloq surgical mask & $2 \pm 0$ & $23 \pm 1$ \\
\hline Bandana, 2 layers ${ }^{a}$ & Levi's Men's printed cotton bandana, red, 2 layers & $55 \pm 5$ & $84 \pm 3$ \\
\hline Heavy-duty tool wipe ${ }^{\text {a }}$ & Sellars ToolBox Z700, 1 layer & $29 \pm 1$ & $53 \pm 5$ \\
\hline Industrial composite filter ${ }^{a}$ & NxN Nano, Style NP097 (MERV16) & $0 \pm 0$ & $4 \pm 2$ \\
\hline Suzhou particle respirator (N95) & Suzhou Sanical Protective N95, P/N: MS 8265 & $<1$ & $<1$ \\
\hline HVAC filter & 3M Filtrete 1900, MERV 13, HVAC Filter, 4 layers & $<1$ & $<1$ \\
\hline Engine filter & $\begin{array}{l}\text { FRAM EXTRA GUARD, 2x Engine protection, CA 9895, } \\
1 \text { layer }\end{array}$ & 13 & 18 \\
\hline Bra cup & $\begin{array}{l}\text { Bra cup, Wire-free Ultra Soft Blissful Benefits by } \\
\text { Warner's, Style RM1691W, color TW/white, } 1 \text { layer }\end{array}$ & 6 & 17 \\
\hline Weed barrier & $\begin{array}{l}\text { Sta-Green Ultimate WeedBarrier Level } 3 \text { Landscaping } \\
\text { Fabric, } 1 \text { layer }\end{array}$ & 5 & 45 \\
\hline Shower curtain & $\begin{array}{l}\text { Shower curtain, water-repellant, embossed, 100\% } \\
\text { polyester, } 1 \text { layer }\end{array}$ & 8 & 45 \\
\hline Cotton pillowcase & $\begin{array}{l}\text { California Design Den, } 100 \% \text { Extra Long Staple Cotton, } \\
600 \text { thread count sateen weave pillowcase, } 2 \text { layers }\end{array}$ & 11 & 44 \\
\hline Microfiber pillowcase & $\begin{array}{l}1800 \text { thread count ultra microfiber pillowcase, Estate } \\
\text { Blue, } 2 \text { layers }\end{array}$ & 21 & 61 \\
\hline Coffee filter & Walmart Great Value white coffee filter basket, 1 layer & 39 & 75 \\
\hline \multirow[t]{2}{*}{ Surgical drape } & 1 layer & 2 & 36 \\
\hline & 2 layers & 1 & 17 \\
\hline
\end{tabular}

a Test aerosol was composed of $\mathrm{NaCl}$.

of cotton bandana were tested, because a bandana is typically folded in half and tied at the back of an individual's head. The concentration of aerosol particles over a range of mean diameters $(10,25,50,100,200,300,400$, and $500 \mathrm{~nm})$ was determined in the absence and presence of each filter sample material.

To test the percent penetration of aerosols of a specific mobility diameter through the filter material, aerosol samples were generated from a $0.05 \mathrm{wt} \%$ salt solution using an atomizer (TSI Model 3076 Constant Output Atomizer) supplied with gaseous $\mathrm{N}_{2}$ (Eninger et al., 2008a). In the initial survey $\left(\mathrm{NH}_{4}\right)_{2} \mathrm{SO}_{4}$, was used due to availability. The subsequent measurements were conducted with sodium chloride $(\mathrm{NaCl})$ to match the particle composition employed by NIOSH for certification tests for $\mathrm{N} 95$ respirators (NIOSH, 2019). It has been previously demonstrated that inert aerosols, such as these two salts, are appropriate analogues for viruses in the testing of filter materials when it is not possible or advisable to atomize viruses (Eninger et al., 2008). Additionally, data was collected for the $\mathrm{N} 95$ respirators using $\mathrm{NaCl}$ and $\left(\mathrm{NH}_{4}\right)_{2} \mathrm{SO}_{4}$ in order to compare penetration by each salt. It was found that the percent penetration of each through the N95 respirator agreed within 5\% across the particle diameter range $25-500 \mathrm{~nm}$. Therefore, the use of the two salts for atomizing solutions does not introduce additional uncertainties into the experimental results.

The aerosol sample flow leaving the atomizer was maintained at a flow rate of $1.0 \pm 0.1 \mathrm{~L} \mathrm{~min}^{-1}$ by drawing off excess flow using a flowmeter (Omega, FL-2000 Series) and pump (Gast, Model DOA-V722-AA). The sample was directed through a diffusion dryer (TSI Model 3062 Diffusion Dryer) containing dried silica gel desiccant and to a differential mobility analyzer (DMA, TSI Series 3080 Electrostatic Classifier) to produce a near monodisperse flow of aerosol of the chosen mobility diameter. The mobility diameter was controlled by selecting the voltage on the DMA charge column to determine which size aerosol exited the DMA. Following data collection, a correction algorithm was applied within the GRIMM software to correct for inaccurate sizing of multiple charged 
particles (He and Dhaniyala, 2013). Throughout the experiment, the DMA sample and sheath flow rates were maintained at constant flows of $1.0 \pm 0.1 \mathrm{~min}^{-1}$ and $5.0 \mathrm{~min}^{-1}$, respectively. Next, the aerosol flow was sent through conductive tubing to a condensation particle counter (CPC, TSI Model 3786 Ultrafine Water-based Condensation Particle Counter) to determine the total concentration of aerosols in the selected size. Data was collected until the particle concentration was stable for several minutes. After the size-specific concentration was measured, flow leaving the DMA was redirected to pass through the sample holder containing the mask material of interest and to the $\mathrm{CPC}$, to determine the concentration of aerosols passing through the filter. Once again, the CPC concentration was allowed to stabilize, and the concentration of aerosols penetrating the filter was determined. The condensation particle counter operated at a constant flow rate of $0.6 \mathrm{~L} \mathrm{~min}^{-1}$ $\left(10 \mathrm{~cm}^{3} \mathrm{~s}^{-1}\right)$, which was maintained throughout all experiments, resulting in a face velocity of $0.72 \mathrm{~cm} \mathrm{~s}^{-1}$ through the filter material (surface area $13.8 \mathrm{~cm}^{2}$ ). The last sixty seconds of each data collection period were averaged in order to determine the mean particle concentration with and without the filter sample material in place for each particle diameter. Then, the percent penetration $C$ was determined for each filter material, as shown in Eq. (2),

$C=\frac{N_{P 1}^{\text {filter }}}{N_{P 1}^{\text {no filter }}} \times 100 \%$

where $N_{P 1}^{\text {fitter }}$ is the concentration of aerosol particles measured by the TSI water CPC with the filter material in place, and $N_{P 1}^{\text {no filter }}$ is the concentration of aerosol particles measured by the TSI water CPC without the filter material in place.

While the conditions in the initial survey were different from those used in the NIOSH 95 test, notably at a lower face velocity of $0.72 \mathrm{~cm} \mathrm{~s}^{-1}$ compared to $9.3 \mathrm{~cm} \mathrm{~s}{ }^{-1}$, this low flow testing provided a rapid method for evaluating whether or not the mask materials removed $95 \%$ as a benchmark for identifying promising candidates for additional testing.

The results of the survey for 100 and $300 \mathrm{~nm}$ aerosol particles are summarized in Table 1. Except where noted in the table, all aerosol samples were generated from an ammonium sulfate $\left(\left(\mathrm{NH}_{4}\right)_{2} \mathrm{SO}_{4}\right)$ solution. Two air filter materials (3M Filtrete 1900 and 3M Filtrete Premium Allergen and Ultrafine Particles) performed similarly to the N95 masks (Suzhou Sanical Protective and 3M Particulate respirator) with percent penetration $\leq 1 \%$ for both 100 and $300 \mathrm{~nm}$ aerosol particles. Additionally, the vacuum bag performed very well, with $1 \%$ penetration for $100 \mathrm{~nm}$ aerosol particles and $6 \%$ penetration for $300 \mathrm{~nm}$ aerosol particles. In contrast, surgical masks exhibited higher percent penetration ( $4 \%$ for $100 \mathrm{~nm}$ aerosol particles, $28 \%$ for $300 \mathrm{~nm}$ aerosol particles), and the percent penetration for coffee filters was even higher ( $39 \%$ for $100 \mathrm{~nm}$ aerosol particles, $75 \%$ for $300 \mathrm{~nm}$ aerosol particles). Out of the fabrics included in this survey, the weed barrier provided the best protection against $100 \mathrm{~nm}$ aerosol particles ( $5 \%$ penetration), followed by the bra cup ( $6 \%$ penetration), though neither of these materials provided adequate protection against $300 \mathrm{~nm}$ aerosol particles (45\% and $17 \%$ penetration, respectively). The double-layered bandana, a common material for homemade or improvised face masks, allowed for the penetration of $28 \%$ of $100 \mathrm{~nm}$ aerosol particles and $72 \%$ of $300 \mathrm{~nm}$ aerosol particles. The microfiber pillowcase, with 1800 threads per inch, slightly outperformed the bandana ( $21 \%$ for $100 \mathrm{~nm}$ aerosol particles, $61 \%$ for $300 \mathrm{~nm}$ aerosol particles) but underperformed compared to the cotton pillowcase, with 600 threads per inch ( $11 \%$ for $100 \mathrm{~nm}$ aerosol particles, $44 \%$ for $300 \mathrm{~nm}$ aerosol particles).

At the initial low face velocity, eight of the seventeen samples failed to limit the percent penetration of $100 \mathrm{~nm}$ particles to $5 \%$ or less. When the particle diameter was increased to $300 \mathrm{~nm}$, twelve of the eighteen samples failed. Following the initial low face velocity survey, we made minor changes to our experimental setup to conduct measurements at higher (and therefore more relevant) face velocities. Changes are indicated in Fig. 1(b). Higher flow rates were achieved by adding a dilution flow line using filtered room air upstream of the mixing chamber and a Gast pump controlled by a flow meter and mass flow controller downstream of the sample material. Subsequent measurements were performed at face velocities of $0.72 \mathrm{~cm} \mathrm{~s}^{-1}, 4.30 \mathrm{~cm} \mathrm{~s}^{-1}$, and $13.0 \mathrm{~cm} \mathrm{~s}^{-1}$.

The middle and highest face velocities were chosen to correspond with average breathing flow rates during light physical work $\left(30.3 \pm 6.2 \mathrm{~L} \mathrm{~min}^{-1}\right)$ and heavy physical work $\left(72.3 \pm 22.9 \mathrm{~L} \mathrm{~min}^{-1}\right)$, respectively (Anderson et al., 2006). Mask surface areas observed in other studies range from 
$150 \mathrm{~cm}^{2}$ to $250 \mathrm{~cm}^{2}$ (Ramirez and O'Shaughnessy, 2017; Schilling et al., 2020). Simulated results show that the face velocity varies across the surface of filters such that only part of the surface area of the filter experiences a nonzero face velocity (Sachinidou et al., 2017). Therefore, the area of the face mask that the wearer breathes through was assumed to be $100 \mathrm{~cm}^{2}$ for the purpose of conversion from breathing flow rate to test velocity. This area results in face velocities of $5.1 \pm$ $1.0 \mathrm{~cm} \mathrm{~s}^{-1}$ for breathing during light physical work and $12.1 \pm 3.8 \mathrm{~cm} \mathrm{~s}^{-1}$ for breathing during heavy physical work. Face mask filtration area will likely vary between individuals due to differences in facial geometry, just as breathing flow rates will vary due to differences in physiology such as gender (Janssen et al., 2005). It should be noted that breathing face velocity may be higher or lower than estimated for various levels of physical work in this manuscript based on interpersonal differences and levels of activity.

The two CPCs used in this study do not report identical particle concentration when sampling from room air, polydisperse single-component aerosol, or monodisperse single-component aerosol, due to differences in internal working fluid (water and butanol) and other instrument parameters. Additionally, the two CPCs were placed at different points in the experimental setup, which could lead to differences in the concentrations measured by the two instruments even if they were identical models. To account for any variations in the concentrations measured by the TSI waterbased CPC and the GRIMM butanol CPC due to differences in instrument performance or particle losses through the respective sample lines, the instruments were cross-calibrated. Three blank runs in which the filter holder was in place, but empty, were performed for each face velocity. The particle concentrations measured by the TSI water-based CPC and the GRIMM butanol CPC were averaged across the three runs. A correction factor $C F$ was determined for each particle diameter and face velocity according to Eq. (3).

$C F=\frac{N_{P 1, \text { blank }}}{N_{P 2, \text { blank }}}$

where $N_{P 1 \text {,blank }}$ is the concentration of aerosol particles measured by the TSI water-based CPC during the blank runs, $N_{P 2}$,blank is the concentration of aerosol particles measured by the Grimm butanol CPC during the blank runs (supplemental Fig. S1). The correction factors were generally less than unity for aerosol particle diameters $>50 \mathrm{~nm}$, and greater than unity for aerosol particle diameters $<50 \mathrm{~nm}$. This may be due to the undercounting of small particles by the water-based CPC.

The correction factor $C F$ was subsequently used to determine the percent penetration for the sample runs as shown in Eq. (4):

$C=\frac{N_{P 1}}{C F N_{P 2}} \times 100 \%$

where $N_{P 1}$ is the concentration of aerosol particles measured by the TSI water-based CPC and $N_{P 2}$ is the corresponding concentration of aerosol particles measured by the Grimm butanol-based CPC during sample runs. The experiments conducted at the three face velocities utilized a smaller number of tested filter materials than the initial survey, including only those which performed relatively well in the initial survey, plus bandanas and three-layer surgical masks due to widespread usage (Table 2).

\subsection{Pressure Drop and Filter Quality}

Pressure drop across the filter is also a factor must also be measured in order to determine the quality of the filter material $q_{f}$, as shown in Eq. (1). The pressure drop $\Delta p$ was determined using Eq. (5)

$\Delta p=p_{\text {up }}-p_{\text {down }}$

where $p_{\text {up }}$ is the pressure in the line upstream from the filter holder, and $p_{\text {down }}$ is the pressure downstream from the filter holder, in $\mathrm{mm} \mathrm{H}_{2} \mathrm{O}$. 
Table 2. Percent penetration of aerosol particles at face velocity $=13.0 \mathrm{~cm} \mathrm{~s}^{-1}$.

\begin{tabular}{llll}
\hline Filter Material & Manufacturer and Other Details & $\begin{array}{l}100 \mathrm{~nm} \text { Percent } \\
\text { Penetration }\end{array}$ & $\begin{array}{l}300 \mathrm{~nm} \text { Percent } \\
\text { Penetration }\end{array}$ \\
\hline 3M particle respirator (N95) & 3M Model 8200/07023 & $1 \pm 1$ & $3 \pm 3$ \\
Allergen filter & 3M Filtrete Premium Allergen and Ultrafine Particles, D & $2 \pm 3$ & $5 \pm 3$ \\
& $\quad$ Filter Size, True HEPA, Model \#1150099, 1 layer & & $31 \pm 5$ \\
Vacuum bag & Vacuum bag, Great Value “Eureka" style RR bag, 1 layer & $34 \pm 12$ & $39 \pm 1$ \\
Surgical mask & Unigard FluidBloq surgical mask & $55 \pm 3$ & $51 \pm 1$ \\
Bandana, 2 layers & Levi's Men's printed cotton bandana (red), 2 layers & $85 \pm 1$ & $26 \pm 1$ \\
Heavy-duty tool wipe & Sellars ToolBox Z700, 1 layer & $50 \pm 1$ & $11 \pm 1$ \\
Industrial composite filter & NxN Nano, Style NP097 (MERV16) & $20 \pm 5$ & \\
\hline
\end{tabular}

\subsection{Structure and Morphology}

The structural and morphological properties of each of the filter materials were examined using scanning electron microscopy (SEM) and an ASTM International approved thickness gauge. Taken together, these measurements provide characterization of the samples, which in most cases, are well-known household materials but are whose structural properties are rarely considered. Secondly, if structural characteristics of the most successful filters can be identified, it may be possible to extrapolate any structure-filter capacity relationships observed to additional materials. For each filter material, the basic structure (woven vs. nonwoven) thickness, mean diameter of fibers, the estimated pore area on each filter and ratio of pore area to total filter area were determined and summarized in Table 3.

The SEM images were obtained with a TESCAN VEGA3 thermionic emission SEM system at the on-campus Microscopy \& Imaging Center at Texas A\&M University. Several of the materials were constructed of multiple layers of materials. In these cases, the layers were separated and analyzed individually. The side of each layer facing incoming unfiltered air was selected to be imaged.

Following SEM image collection, ImageJ analysis software was used to measure the fiber diameter and projected pore area. The diameters of ten fibers were measured for each layer in each sample, and corresponding average diameter and standard deviation were calculated. Some individual layers consist of multiple types of fibers with different diameters, and each type of fiber was measured separately.

A semi-quantitative assessment of 3D porosity can be obtained by analyzing high resolution 2D SEM images to determine the projects pore area (Pentyala et al., 2018; Yang et al., 2020; Zou et al., 2020). The projected pore areas were measured using ImageJ software. For each sample, the color threshold values were manually adjusted to best distinguish between pores identifiable as darker areas in the image with either no visible fiber or minimal stray fibers and filter material. Automated ImageJ box counting was then used to measure the area of all the pores in the SEM image. The projected pore area ratio is calculated by dividing the pore area by the total imaging area. The error of the $2 \mathrm{~d}$ projected pore ratio is calculated by calculating standard deviation from pore ratio measured on 4 SEM images of a typical sample, and we assume measurement on every sample share the same error.

The thickness of each filter material was measured with a Mitutoyo 547-500S Digital Thickness Gauge which meets ASTM standards. For consistency, the thickness gauge measures thickness under a constant applied measuring force of $1.5 \mathrm{~N}$. The thickness of each sub-layer of each sample was measured separately 10 times, with which an average and a standard deviation were taken.

\section{RESULTS AND DISCUSSION}

The variation of percent penetration with face velocity is shown for $100 \mathrm{~nm}$ particles in Fig. 2(a) and $300 \mathrm{~nm}$ particles in Fig. 2(b). The percent penetration of $100 \mathrm{~nm}$ particles increased with face velocity for most of the materials, whereas the percentage of $300 \mathrm{~nm}$ particles penetrating the material decreased with face velocity or followed no trend, depending on the material. According to classic filtration theory, the dominant filtration process for $100 \mathrm{~nm}$ particles is through diffusion by Brownian motion. Increased velocities reduce the time available for diffusion, which in turn 
Table 3. Fabric micro-structure and morphology.

\begin{tabular}{|c|c|c|c|c|c|}
\hline Filter Material & Type & Thickness (mm) & Fiber size $(\mu \mathrm{m})$ & Filter Pore Area $\left(\mathrm{cm}^{2}\right)$ & Pore Ratio \\
\hline \multirow[t]{3}{*}{ 3M particle respirator (N95) } & Non-woven & $0.68 \pm 0.11$ & $26.32 \pm 1.41$ & $1.54 \pm 0.54$ & $0.11 \pm 0.04$ \\
\hline & Non-woven & $0.30 \pm 0.03$ & $1.04 \pm 0.02$ & $1.04 \pm 0.54$ & $0.08 \pm 0.04$ \\
\hline & Non-woven & $0.52 \pm 0.08$ & $22.18 \pm 0.77$ & $1.38 \pm 0.54$ & $0.10 \pm 0.04$ \\
\hline \multirow[t]{2}{*}{ Allergen filter } & Non-woven & $0.33 \pm 0.02$ & $1.44 \pm 0.15$ & $0.87 \pm 0.54$ & $0.06 \pm 0.04$ \\
\hline & Non-woven & $0.43 \pm 0.02$ & $37.56 \pm 1.80$ & $1.25 \pm 0.54$ & $0.09 \pm 0.04$ \\
\hline \multirow[t]{2}{*}{ Vacuum bag } & Non-woven & $0.14 \pm 0.01$ & $2.90 \pm 0.37$ & $0.90 \pm 0.54$ & $0.07 \pm 0.04$ \\
\hline & Non-woven & $0.18 \pm 0.01$ & $46.97 \pm 3.59$ & $2.56 \pm 0.54$ & $0.19 \pm 0.04$ \\
\hline \multirow[t]{3}{*}{ Surgical mask } & Non-woven & $0.14 \pm 0.02$ & $25.56 \pm 2.27$ & $4.12 \pm 0.54$ & $0.30 \pm 0.04$ \\
\hline & Non-woven & $0.14 \pm 0.01$ & $1.56 \pm 0.26$ & $3.34 \pm 0.54$ & $0.24 \pm 0.04$ \\
\hline & Non-woven & $0.20 \pm 0.03$ & $22.96 \pm 1.56$ & $2.66 \pm 0.54$ & $0.19 \pm 0.04$ \\
\hline Bandana, 2 layers & Woven & $0.27 \pm 0.01$ & $270.48 \pm 23.45$ & $1.12 \pm 0.54$ & $0.08 \pm 0.04$ \\
\hline \multirow[t]{2}{*}{ Heavy-duty tool wipe } & Non-woven & $0.25 \pm 0.01$ & $20.60 \pm 3.99$ & $0.26 \pm 0.54$ & $0.02 \pm 0.04$ \\
\hline & Non-woven & $0.25 \pm 0.01$ & $22.53 \pm 1.87$ & $0.26 \pm 0.54$ & $0.02 \pm 0.04$ \\
\hline \multirow[t]{3}{*}{ Industrial composite filter } & Non-woven & $0.24 \pm 0.01$ & $16.63 \pm 0.60$ & $1.58 \pm 0.54$ & $0.11 \pm 0.04$ \\
\hline & Non-woven & $0.24 \pm 0.01$ & $17.25 \pm 1.45$ & $1.44 \pm 0.54$ & $0.10 \pm 0.04$ \\
\hline & Non-woven & $0.35 \pm 0.04$ & $16.13 \pm 0.86$ & $2.99 \pm 0.54$ & $0.22 \pm 0.04$ \\
\hline \multirow[t]{4}{*}{ Suzhou particle respirator (N95) } & Non-woven & $0.38 \pm 0.02$ & $23.16 \pm 0.86$ & $0.92 \pm 0.54$ & $0.07 \pm 0.04$ \\
\hline & Non-woven & $0.73 \pm 0.11$ & $20.28 \pm 1.75$ & $0.22 \pm 0.54$ & $0.02 \pm 0.04$ \\
\hline & Non-woven & $0.34 \pm 0.01$ & $5.89 \pm 0.48$ & $0.44 \pm 0.54$ & $0.03 \pm 0.04$ \\
\hline & Non-woven & $0.15 \pm 0.01$ & $20.64 \pm 1.14$ & $1.75 \pm 0.54$ & $0.13 \pm 0.04$ \\
\hline HVAC filter & Non-woven & $0.48 \pm 0.05$ & $15.48 \pm 1.16$ & $0.34 \pm 0.54$ & $0.02 \pm 0.04$ \\
\hline Engine filter & Non-woven & $0.67 \pm 0.08$ & $33.74 \pm 13.82$ & $0.50 \pm 0.54$ & $0.04 \pm 0.04$ \\
\hline \multirow[t]{2}{*}{ Bra cup } & Woven & $0.31 \pm 0.01$ & $8.22 \pm 0.61$ & $0.91 \pm 0.54$ & $0.07 \pm 0.04$ \\
\hline & Woven & $2.60 \pm 0.20$ & $8.94 \pm 0.50$ & $1.84 \pm 0.54$ & $0.13 \pm 0.04$ \\
\hline Weed barrier & Non-woven & $0.47 \pm 0.02$ & $29.89 \pm 1.78$ & $0.87 \pm 0.54$ & $0.06 \pm 0.04$ \\
\hline Shower curtain & Non-woven & $0.22 \pm 0.00$ & $12.21 \pm 1.68$ & $0.37 \pm 0.54$ & $0.03 \pm 0.04$ \\
\hline Cotton pillowcase & Woven & $0.26 \pm 0.00$ & $17.41 \pm 2.56$ & $0.55 \pm 0.54$ & $0.04 \pm 0.04$ \\
\hline Microfiber pillowcase & Woven & $0.21 \pm 0.00$ & $12.97 \pm 2.12$ & $0.51 \pm 0.54$ & $0.04 \pm 0.04$ \\
\hline Coffee filter & Non-woven & $0.08 \pm 0.00$ & $30.67 \pm 13.79$ & $0.32 \pm 0.54$ & $0.02 \pm 0.04$ \\
\hline \multirow[t]{2}{*}{ Surgical drape } & Non-woven & $0.34 \pm 0.01$ & $15.77 \pm 0.65$ & $0.31 \pm 0.54$ & $0.02 \pm 0.04$ \\
\hline & Non-woven & $0.36 \pm 0.02$ & $18.45 \pm 2.41$ & $0.31 \pm 0.54$ & $0.05 \pm 0.04$ \\
\hline
\end{tabular}

\begin{tabular}{|c|c|c|}
\hline $\begin{array}{l}\mathrm{I} \text {-3M particulate respirator (N95) } \\
\mathrm{I} \text { Allergen filter } \\
\mathrm{I} \text { Vacuum bag }\end{array}$ & $\begin{array}{l}\overline{\mathrm{I}} \text { Surgical mask } \\
\frac{\mathrm{I}}{\mathrm{I}} \text { Bandana, } 2 \text { layers } \\
\text { Heavy-duty tool wipe }\end{array}$ & $\mathrm{I}$ Industrial composite filter \\
\hline
\end{tabular}
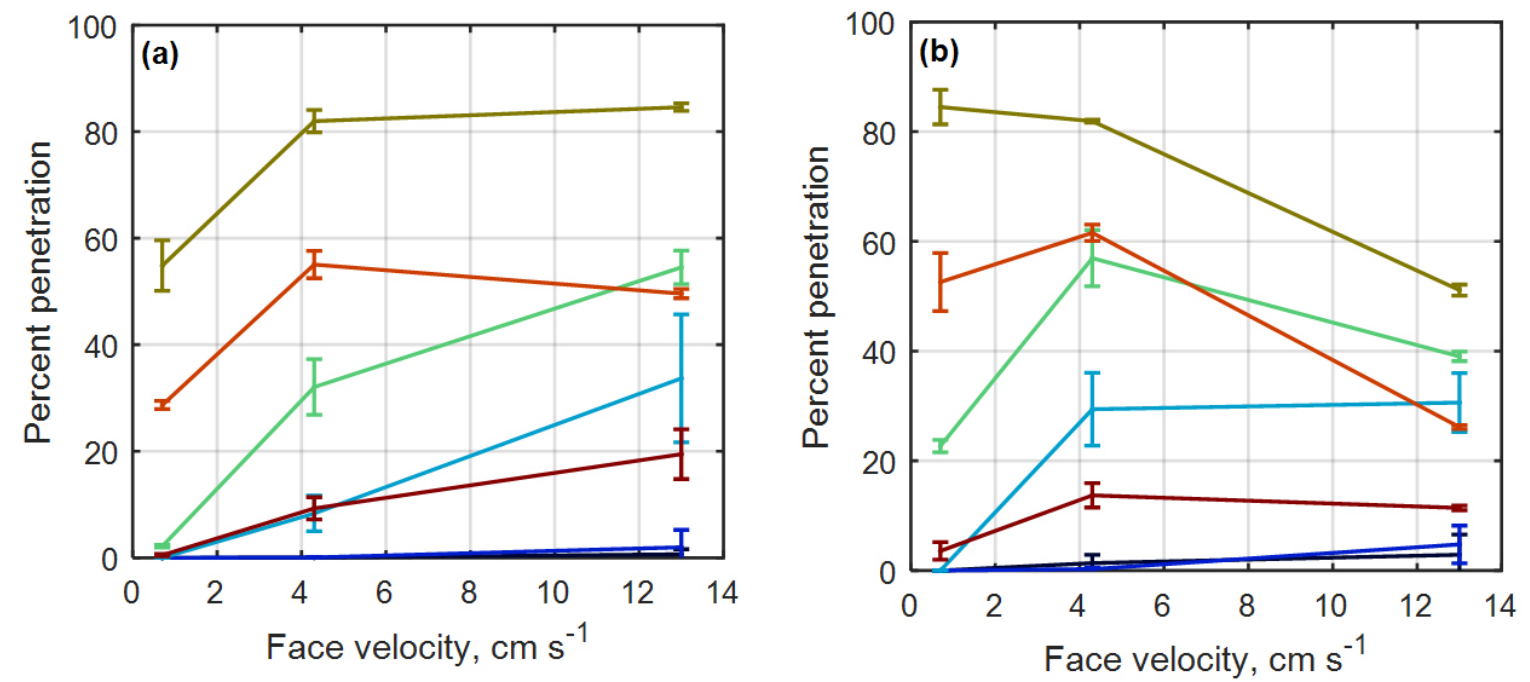

Fig. 2. Percent penetration as a function of face velocity for (a) $100 \mathrm{~nm}$ and (b) $300 \mathrm{~nm} \mathrm{NaCl}$ aerosol particles. 
decreases the fraction of particles which can penetrate the filter through diffusion. For $300 \mathrm{~nm}$ aerosol particles, diffusion remains significant, but deposition due to impaction and interception (which increase with velocity) are greater. An increase in percent penetration with face velocity results from a decrease in collection due to diffusion, without a concomitant increase in collection due to impaction or interception. Collection by diffusion is most efficient for smaller aerosol particles (and for lower face velocity), while collection by impaction and interception is more efficient for larger aerosol particles (and for higher face velocity) (Huang et al., 2013). As a result, some of the materials may preferentially remove particles by one mechanism or another due to their structures and morphologies. For example, as shown in Figs. 3(b) and 3(c), the surgical mask and the heavy-duty tool wipe collect larger particles with approximately the same level of efficiency, but the surgical mask is more effective in capturing smaller particles than the heavyduty tool wipe.

Percent penetration as a function of particle diameter over the range $25-500 \mathrm{~nm}$ is reported in Fig. 3, as the mean (and standard deviation) of the three replicates for each filter material and face velocity. For reference, the $100 \mathrm{~nm}$ and $300 \mathrm{~nm}$ data at the highest face velocity $\left(13.0 \mathrm{~cm} \mathrm{~s}^{-1}\right)$ are also summarized in Table 2. A standard threshold for percent penetration was set to $5 \%$, which is the same standard that is used in N95 certification. Here, this standard is used across the range of face velocities employed due to the fact that different standards have not been established for individual face velocities. Unfortunately, the only filter materials for which 25$500 \mathrm{~nm}$ particle penetration did not exceed $5 \%$ at the highest face velocity were the N95 respirator and the allergen filter. Considering $300 \mathrm{~nm}$ particles at the highest face velocity, the $\mathrm{N} 95$ material allows passage of $3 \%$ of particles. The next best material was the allergen filter which allowed $5 \%$ penetration of $300 \mathrm{~nm}$ particles, followed by the industrial composite filter which allowed $11 \%$ penetration of $300 \mathrm{~nm}$ particles. The surgical mask failed to meet the $\leq 5 \%$ threshold at $4.30 \mathrm{~cm} \mathrm{~s}^{-1}$ for particles with diameter greater than $75 \mathrm{~nm}$ and failed for all diameters at $13.0 \mathrm{~cm} \mathrm{~s}^{-1}$. This is in agreement with another study which found that surgical masks do not provide adequate protection from the inhalation of submicron aerosol particles (Maclntyre and Chughtai, 2015). The weakest
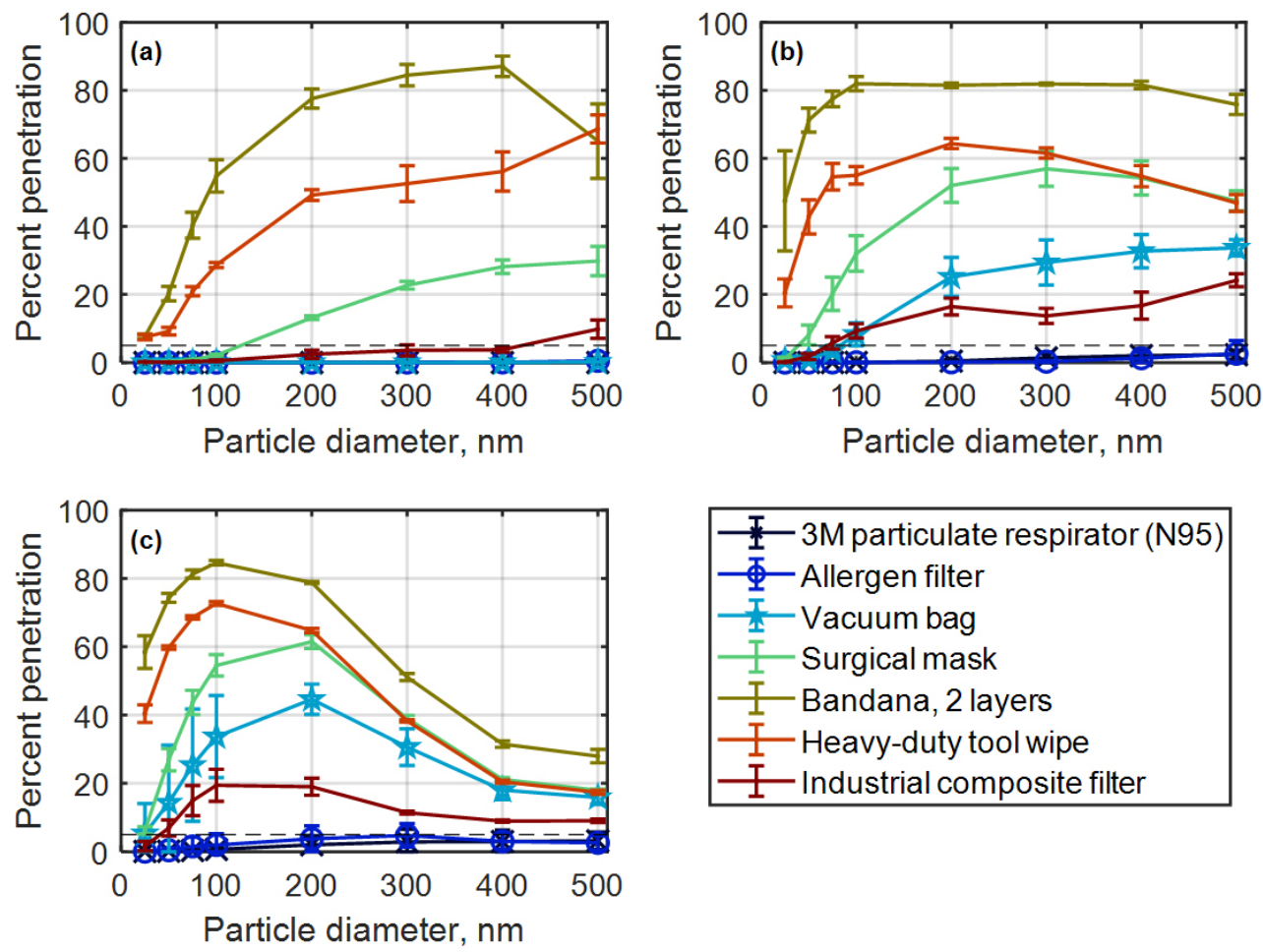

Fig. 3. Percent penetration as a function of particle size at a face velocities of $0.72 \mathrm{~cm} \mathrm{~s}^{-1}$, $4.30 \mathrm{~cm} \mathrm{~s}^{-1}$, and $13.0 \mathrm{~cm} \mathrm{~s}^{-1}$ are shown in (a), (b) and (c), respectively. The dashed lines indicate $5 \%$ penetration. Markers have been added to the data points for the first three materials in an effort to show that overlapping results for these materials. 
performance was observed for the bandana, which allowed $51 \%$ penetration of $300 \mathrm{~nm}$ and $85 \%$ penetration of the $100 \mathrm{~nm}$ at the highest face velocity. These results compare well with Zhao et al. (2020), which found $\geq 70 \%$ percent penetration for various cotton, silk, nylon, and polyester fabrics. In contrast, Konda et al. (2020) found $<35 \%$ penetration for a single layer of 600 TPI cotton, 45-60\% penetration for a single layer of silk, and 45-75\% penetration for a single layer of flannel.

According to a study on cough-generated aerosol particles, 4000-8000 particles with diameters 350-500 $\mathrm{nm}$ may be generated from a single cough from an individual infected with influenza (Lindsley et al., 2010). This study indicates that it is important to limit the inhalation of the two largest diameters in our study. Interestingly, the percent of 400 and $500 \mathrm{~nm}$ particles that penetrated all but two of the filter sampler materials (N95 respirator, allergen filter) is higher at the face velocity representative of light or moderate work $\left(4.3 \mathrm{~cm} \mathrm{~s}^{-1}\right)$ than at the higher face velocity used here to represent a higher degree of physical exertion $\left(13.0 \mathrm{~cm} \mathrm{~s}^{-1}\right)$. This suggests that the "alternative" materials provide better protection against $400-500 \mathrm{~nm}$ aerosol particles if one's activity level is increased.

The pressure drops across each filter material (in $\mathrm{mm} \mathrm{H}_{2} \mathrm{O}$ ) for each face velocity are shown in Fig. 4. For all materials tested, pressure drop increases with face velocity, and the relationship between the two is approximately linear. Additionally, pressure drop varies greatly with material. It should be noted that NIOSH certification testing 42 CFR 84.180 requires pressure drops across candidate materials to not exceed $35 \mathrm{~mm} \mathrm{H} \mathrm{H}_{2} \mathrm{O}$ via inhalation or $25 \mathrm{~mm} \mathrm{H} \mathrm{H}_{2} \mathrm{O}$ via exhalation at a face velocity of $9.3 \mathrm{~cm} \mathrm{~s}^{-1}$ (NIOSH, 1995; Rengasamy et al., 2017). The pressure drops measured for each material at $4.30 \mathrm{~cm} \mathrm{~s}^{-1}$ (the face velocity that corresponds with breathing during light physical work) fell in the range $0-14 \mathrm{~mm} \mathrm{H}_{2} \mathrm{O}$. While the highest face velocity tested is greater than that in the NIOSH testing, it was included here as it represents breathing during heavy physical work. it is unfortunately that all of the candidate materials exceed the pressure drop limit of $35 \mathrm{~mm} \mathrm{H} \mathrm{H}_{2} \mathrm{O}$ at this face velocity which represents breathing during many activities. Therefore, a person who is resting or performing light physical work will be wearing an adequate mask. Unfortunately for a person engaging in heavier physical work, the pressure drop exceeds the $\mathrm{NIOSH}$ limit for all materials tested.

The filter quality values of each filter material (in $\mathrm{mm} \mathrm{H}_{2} \mathrm{O}^{-1}$ ) for each face velocity are shown in Fig. 5. According to an interim guidance released by the WHO on June 5, 2020, the minimum recommended filter quality for a face mask is approximately $0.03 \mathrm{~mm} \mathrm{H}_{2} \mathrm{O}^{-1}$ (WHO, 2020). This

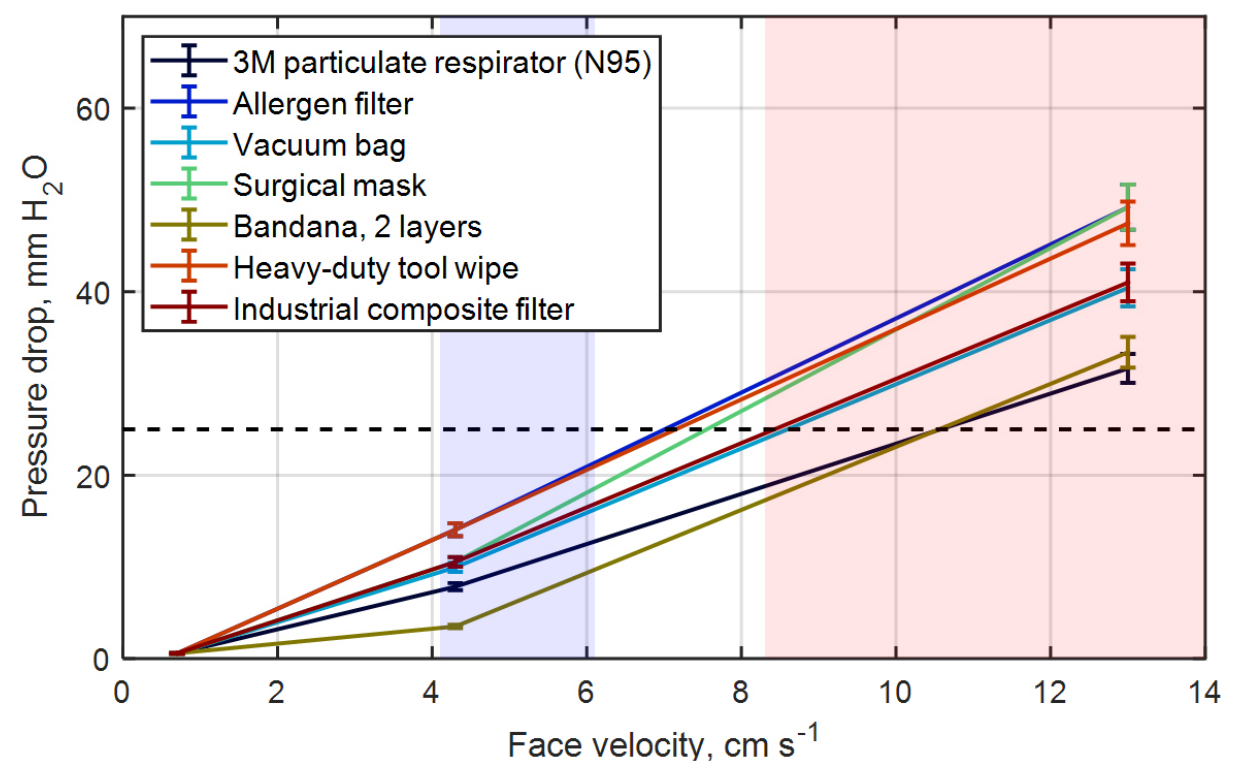

Fig. 4. Pressure drop across each filter material is shown. The dashed line indicates the maximum pressure drop allowed in NIOSH testing, $25 \mathrm{~mm} \mathrm{H} \mathrm{H}_{2} \mathrm{O}$, based on human breath during exhalation. The blue shaded region indicates the face velocities observed during light physical work and the red shaded region indicates the face velocities observed during heavy physical work, according to the breathing flow rates given in Anderson et al. (2006) and assuming a filtration area of $100 \mathrm{~cm}^{2}$. 

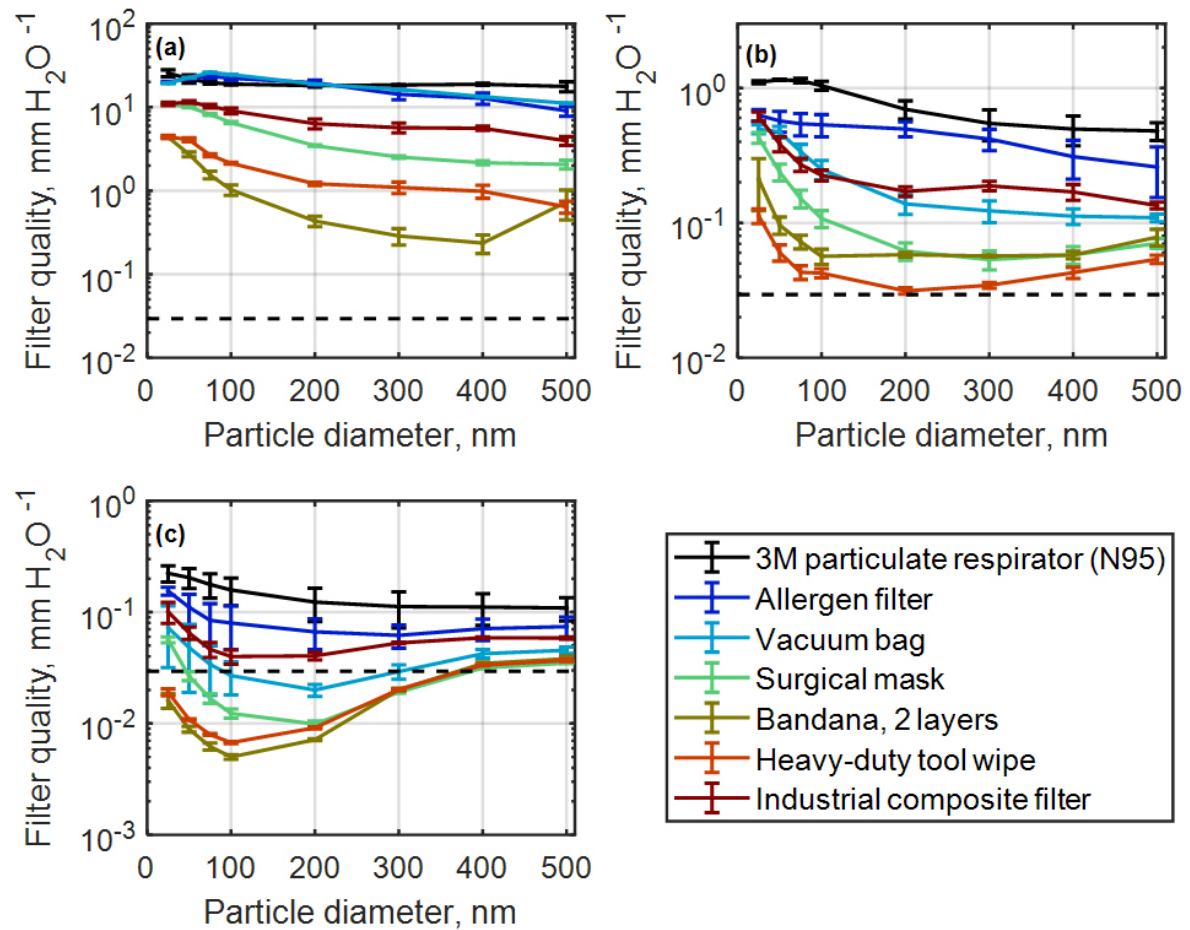

Fig. 5. Filter quality of each sample for a face velocity of $0.72 \mathrm{~cm} \mathrm{~s}^{-1}, 4.30 \mathrm{~cm} \mathrm{~s}^{-1}$, and $13.0 \mathrm{~cm} \mathrm{~s}^{-1}$ are shown in (a), (b), and (c), respectively. The dashed line represents the minimum filter quality recommended by an interim guidance published by the WHO on June 5, 2020 (reference number WHO/2019-nCov/IPC_Masks/2020.4).

threshold is met or exceeded by all candidate materials and particle diameters at $4.3 \mathrm{~cm} \mathrm{~s}^{-1}$, and by the N95 respirator, the allergen filter, and the industrial composite filter for all particle diameters at $13.0 \mathrm{~cm} \mathrm{~s}^{-1}$. The vacuum bag only falls short for $200 \mathrm{~nm}$ aerosol particles, while the surgical mask fails to meet this threshold for 75-300 nm aerosol particles. The heavy-duty tool wipe and the bandana only meet or exceed the minimum filter quality for aerosol particles with diameters greater than or equal to $400 \mathrm{~nm}$. A recently-published study (Hao et al., 2020) determined the filter qualities of an $\mathrm{N} 95$ respirator $\left(0.06 \mathrm{~mm} \mathrm{H}_{2} \mathrm{O}^{-1}\right)$, a vacuum bag $\left(0.03 \mathrm{~mm} \mathrm{H}_{2} \mathrm{O}^{-1}\right)$, household air filters $\left(0.04-0.07 \mathrm{~mm} \mathrm{H}_{2} \mathrm{O}^{-1}\right)$, a surgical mask $\left(0.03 \mathrm{~mm} \mathrm{H}_{2} \mathrm{O}^{-1}\right)$, and a bandana $\left(0.004 \mathrm{~mm} \mathrm{H}_{2} \mathrm{O}^{-1}\right)$, which compare well with the filter qualities determined in our study for the breathing-relevant face velocities $4.30 \mathrm{~cm} \mathrm{~s}^{-1}$ and $13.0 \mathrm{~cm} \mathrm{~s}^{-1}$.

Ranking the materials by filter quality, at the highest face velocity the most effective material is the N95 respirator, followed by the allergen filter, the industrial composite filter, the vacuum bag, the surgical mask, and the heavy-duty tool wipe in descending order. The bandana is the least effective option, even though two layers of the fabric were used in each sample. Interestingly, the ranking of materials for mask construction varies if the materials are ranked according to percent penetration or filter quality. For example, the bandana is ranked seventh in percent penetration at $4.3 \mathrm{~cm} \mathrm{~s}^{-1}$, but it is ranked sixth according to filter quality because its pressure drop is lower than the heavy-duty tool wipe. At $13.0 \mathrm{~cm} \mathrm{~s}^{-1}$, however, the bandana is ranked seventh in both percent penetration and filter quality.

Filter quality also varies with particle diameter for each filter material and face velocity. At the highest face velocity in this study, $13.0 \mathrm{~cm} \mathrm{~s}^{-1}$, the filter quality of the $\mathrm{N} 95$ respirator and allergen filter decreases with particle diameter, while the filter quality of the remaining samples is lowest at 100-200 nm, and increases for particle diameters $>200 \mathrm{~nm}$. In practice, many of the test materials would not be used independently, but rather would be installed as a layer within a face mask. To represent two layers of cotton which would be used to make a simple mask, two layers of cotton bandana were added to one layer of the allergen filter, the vacuum bag, and the heavyduty tool wipe. The percent penetration for each of these combinations at $13.0 \mathrm{~cm} \mathrm{~s}^{-1}$ is shown in Fig. 6(a), and the N95 particulate respirator results from above are included as a reference. 
The percent of particles that penetrated through each combination varied from $0 \% \pm 1 \%$ to $6 \% \pm$ $6 \%$ for the bandana and allergen filter, $1 \% \pm 1 \%$ to $42 \% \pm 2 \%$ for the bandana and vacuum filter, and $20 \% \pm 1 \%$ to $67 \% \pm 1 \%$ for the bandana and heavy-duty tool wipe across the aerosol particle diameters studied. The percent penetration through the combination of the bandana and allergen filter is similar to that observed for combinations of fabrics in Konda et al. (2020), though the percent penetration for the other two combinations in our study are much higher. The other two combinations, in which the vacuum bag and the heavy-duty tool wipe were combined with two layers of bandana, allowed greater particle penetration than observed for the layered materials by Konda et al. (2020).

The pressure drop across each combination was also measured as shown in Fig. 6(b). Each combination was then compared with the performance of the allergen filter, vacuum bag, or heavyduty tool wipe on its own in terms of percent penetration and pressure drop (Figs. 6(c) and 6(d) respectively). Percent penetration through the allergen filter decreased for $50-300 \mathrm{~nm}$ particles (by $-49 \% \pm 169 \%$ to $-82 \% \pm 168 \%$ ). The large uncertainty in the decrease in percent penetration through the allergen filter is due to the low percent penetration, and therefore high ratio of uncertainty to the measured value, before and after the addition of the cotton bandana material. Percent penetration through the heavy-duty tool wipe decreased for 25-300 nm particles (by $-4 \% \pm 3 \%$ to $-16 \% \pm 7 \%$ ). Within the uncertainty in the measurements, the penetration of 25,400 , and $500 \mathrm{~nm}$ particles through the allergen filter, 25-500 nm particles through the vacuum bag, and 400 and $500 \mathrm{~nm}$ particles through the heavy-duty tool wipe, were unchanged.

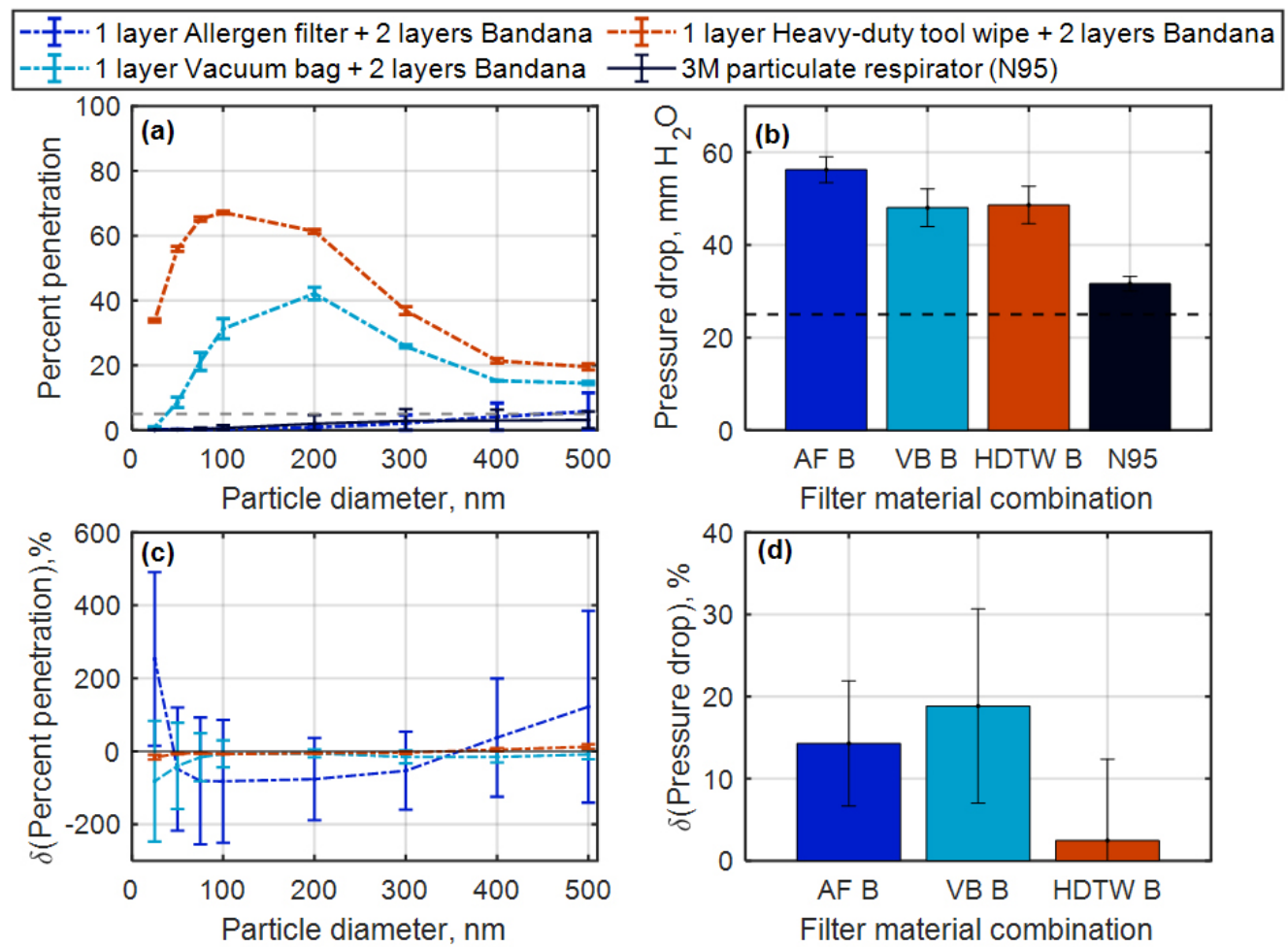

Fig. 6. (a) The percent of particles that penetrated each filter/bandana combination at face velocity $13.0 \mathrm{~cm} \mathrm{~s}^{-1}$ are shown. The percent penetration for the $\mathrm{N} 95$ particulate respirator from Fig. $3(\mathrm{c})$ is shown as a reference. The gray dashed line indicates the $5 \%$ penetration cutoff for N95 certification. (b) The pressure drops across each filter/bandana combination are shown (AF B = one layer of allergen filter and two layers of bandana, VB B = one layer of vacuum bag and two layers of bandana, and HDTW B = one layer of heavy-duty tool wipe and two layers of bandana). The black dashed

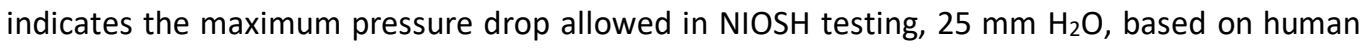
breath during exhalation. (c) The percent change in penetration percent, relative to the filter material without the two layers of bandana, was calculated for each filter/bandana combination. (d) The percent change in pressure drop, relative to the filter material without the two layers of bandana, was calculated for each filter/bandana combination. 
The observed pressure drop for the allergen filter and the vacuum bag also increased when combined with two layers of cotton, 7.0 and $7.6 \mathrm{~mm} \mathrm{H}_{2} \mathrm{O}$, respectively. The resulting pressure drops across each filter/bandana combination are higher than the maximum allowed pressure drop for $\mathrm{N} 95$ certification, $25 \mathrm{~mm} \mathrm{H} \mathrm{m}_{2} \mathrm{O}$. In summary, in some cases the combination of filter materials with two layers of cotton fabric improved their ability to filter particles, though this improvement was offset by the increases in pressure drop for some of the samples. The filter quality of the allergen filter somewhat increased for particle diameters $75-300 \mathrm{~nm}(9 \% \pm 40 \%$ to $26 \% \pm 35 \%)$, and somewhat decreased for particle diameters $25 \mathrm{~nm}(-27 \% \pm 10 \%), 50 \mathrm{~nm}(-2 \% \pm 31 \%), 400 \mathrm{~nm}(-20 \% \pm 34 \%)$, and $500 \mathrm{~nm}(-32 \% \pm 34 \%)$, though the uncertainty in these measurements is high enough to show that these changes were not significant. The addition of the two layers of cotton bandana to the vacuum bag resulted in filter quality changes of $-12 \% \pm 7 \%$ to $34 \% \pm 56 \%$. Filter quality generally increased for the heavy-duty tool wipe, with increases of $10 \% \pm 3 \%$ to $22 \% \pm 3 \%$ for 25-200 $\mathrm{nm}$ particles and negligible change or small decreases for 300-500 $\mathrm{nm}$ particles. In contrast to recently published studies, samples utilizing mixed materials did not exhibit a significant difference in the measured percent penetration when compared to the product of the individual percent penetration for the components. The percent penetration decreased monotonically, and the pressure drop across the filter material increased monotonically, with the number of cloth layers for a lightweight flannel (Zangmeister et al., 2020), suggesting that multilayered cloth masks may offer increased protection from nanometer-sized aerosol with a minimum percent penetration dictated by breathability (i.e., pressure drop). Another recent study found that some combinations of fabrics (denim, quilting cotton fabric, terry cloth, and flannel) and polypropylene nonwoven fabric offered protection against particle transmission that was equivalent to or better than N95 masks, though other combinations offered poorer protection than N95 masks (Lustig et al., 2020). Similarly, one of the three combinations tested in the current study approached the percent penetration through an $\mathrm{N} 95$ particulate respirator (the combination of one layer of allergen filter and two layers of bandana, while the percent penetration through the other two combinations was significantly higher.

In order to understand how the differences in the filtration properties of the materials arose from their physical structures, each material was studied via scanning electron microscopy (SEM). SEM images showing the morphology and distribution of pores in the seven representative filter materials are shown in Fig. 7, and images for all additional tested materials are shown in the supplemental Figs. S1 and S2. Results are summarized in Table 3. Reported errors in fiber diameter, pore area and the ratio of pore area to total material area, are determined from the standard deviation of measurements on 4 SEM images for each sample. For samples that contained more than 1 layer, the structural characteristics of each layer are reported independently.

Six of the materials (N95 particulate respirator, allergen filter, vacuum bag, surgical mask, industrial composite filter, and heavy-duty tool wipe) were composed of 2-3 layers of non-woven materials and the final material (bandana) was composed of one woven fabric layer. Three of the materials which only contained non-woven layers N95 particulate respirator, allergen filter, industrial composite filter) were the strongest performers in terms of percent penetration and filter quality throughout the study, followed by the vacuum bag. The surgical mask did not perform as strongly as the other three materials which were composed of only non-woven layers, though this may have resulted from its lower thickness compared to the N95 particulate respirator, allergen filter, and industrial composite filter. Percent penetration through the vacuum bag (which was composed of two non-woven layers) was greater than that for the industrial composite filter, but lower than that for the surgical mask, at the breathing-relevant face velocities. The weakest performer in the study, with the highest percent penetration and low filter quality, was the only woven material (bandana), followed by a composite of two non-woven layers (heavy-duty tool wipe).

Thickness and fiber diameter also influence the percent penetration of particles through, and the pressure drop across, the filter material. In a previous study of engineered nanomaterials used for face mask construction, thicker mask materials resulted in reduced maximum flowrate and increased pressure drop (El-Atab et al., 2020). This conflicts with the results of the current study, in which no relationship between material thickness and pressure drop was observed. Another recent study found that percent penetration was positively correlated with fiber diameter and negatively correlated with fiber thickness (Bian et al., 2020). The three materials with the greatest thickness (N95 particulate respirator $1.5 \mathrm{~mm}$, industrial composite filter $0.83 \mathrm{~mm}$, 
allergen filter $0.75 \mathrm{~mm}$ ) were associated with the lowest measured percent penetration values, while the highest percent penetration was observed for the thinnest material (bandana, $0.27 \mathrm{~mm}$ ). However, the vacuum bag was only slightly thicker $(0.32 \mathrm{~mm})$ but it outperformed the surgical mask $(0.58 \mathrm{~mm})$ and the heavy-duty tool wipe $(0.50 \mathrm{~mm})$ as well as the bandana. Comparisons of fiber diameter are complicated due to the variation in fiber diameter of the layers in each material. The thinnest fibers $(<5 \mu \mathrm{m})$ are found in non-woven layers in the N95 particulate respirator $(1.04 \mu \mathrm{m})$, allergen filter $(1.44 \mu \mathrm{m})$, vacuum bag $(2.90 \mu \mathrm{m})$, and surgical mask $(1.56 \mu \mathrm{m})$. While the N95 particulate respirator and the allergen filter were among the strongest performers in this study, the vacuum bag and the surgical mask only performed moderately well. The industrial composite

\section{$3 \mathrm{M}$ particle respirator $(\mathrm{N} 95)$}

Allergen filter

Vacuum bag

Surgical mask
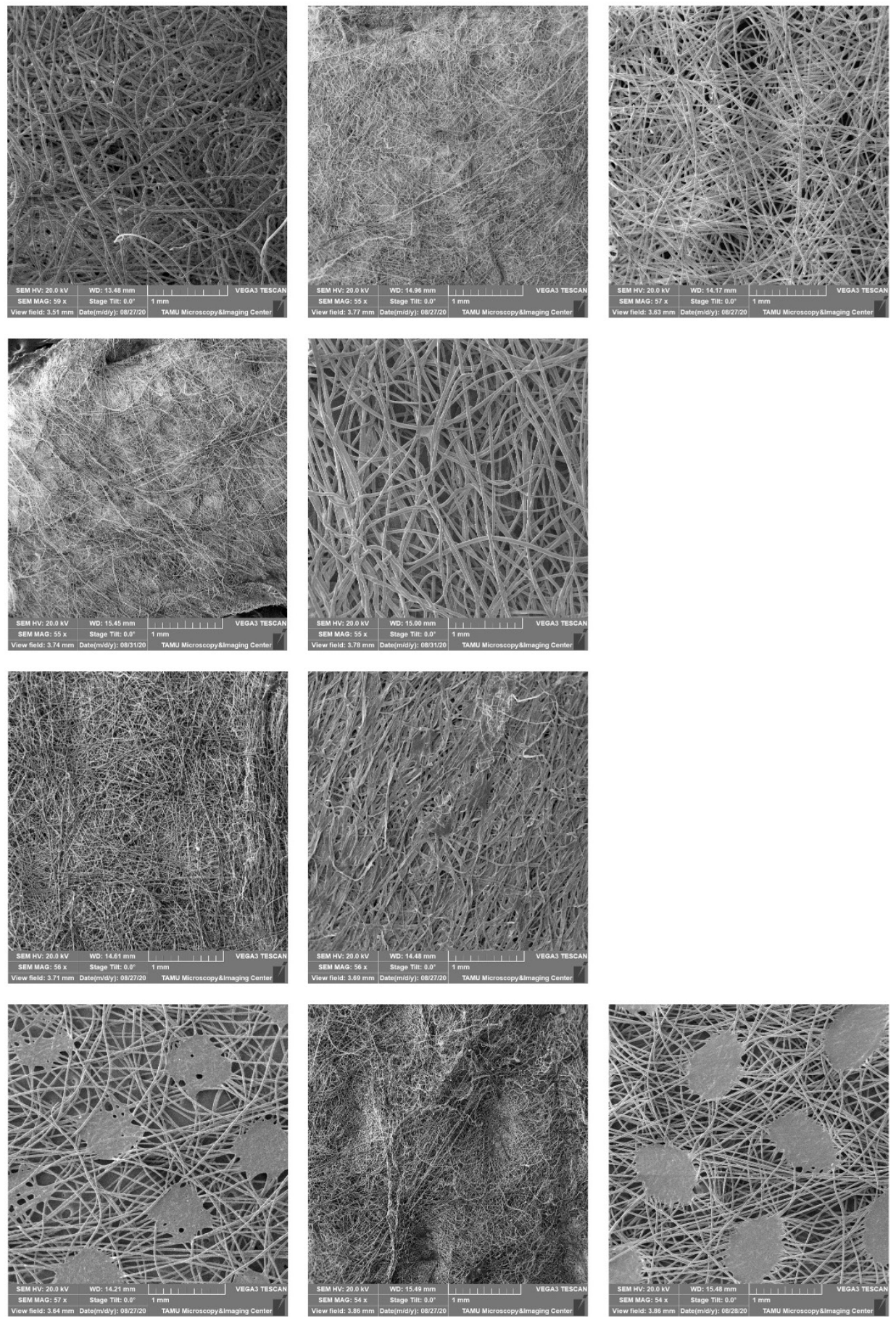

Fig. 7. (a) SEM images of first four filter materials are shown. Magnification for each image is approximately $50 \pm 5 X$. For materials composed of multiple layers, an image of each layer is included. 
Bandana, 2 layers

Heavy-duty tool wipe
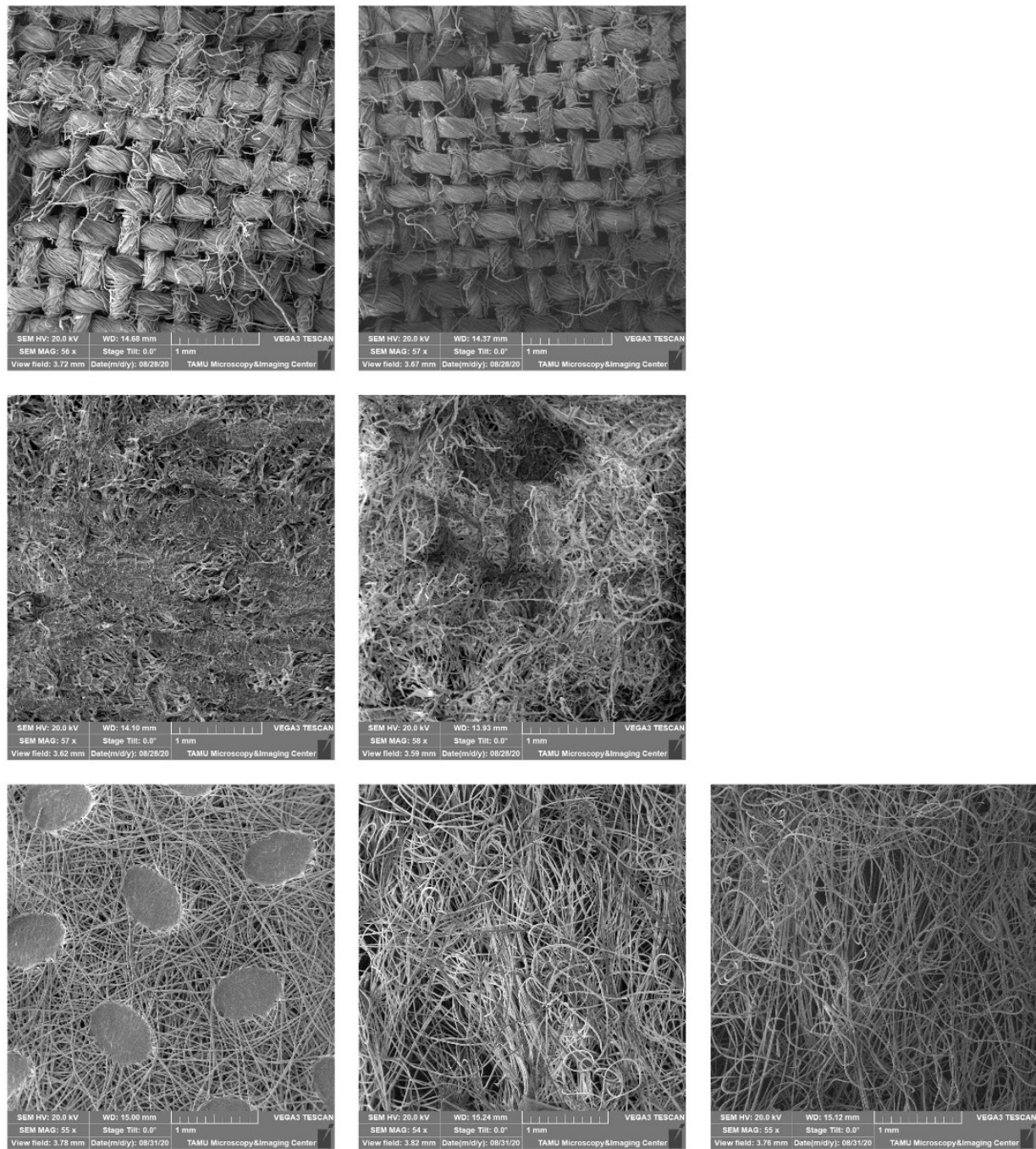

Fig. 7. (b) SEM images of last 3 filter materials are shown. Magnification for each image is approximately $50 \pm 5 X$. For materials composed of multiple layers, an image of each layer is included.

filter, which was only surpassed by the N95 particulate filter and the allergen filter, did not contain fibers with diameter $<15 \mu \mathrm{m}$ in any of its three layers. The heavy-duty tool wipe was also composed of layers with thicker fiber diameter $(20.60 \mu \mathrm{m}$ and $22.53 \mu \mathrm{m})$. The bandana, associated with the highest percent penetration values, contained the thickest fibers of any of the materials in this study $(270.48 \mu \mathrm{m})$. However, it has already been noted that the bandana only contained one layer of woven fabric, and that the thickness of the bandana was lower than that of the other materials, and therefore it cannot be determined that the larger fiber diameter in the bandana was the cause for its high percent penetration. Pore area was not found to correlate with percent penetration or pressure drop through the filter materials. These results are in contrast with previous findings that larger pore sizes are correlated with lower pressure drops (El-Atab et al., 2020).

The biocompatibility of filter material candidates is also a consideration in DIY mask design. A mask material is considered biocompatible if its use does not result in additional health risks due to cytotoxicity, carcinogenicity, reproductive toxicity, or skin irritation (CEN, 2009). Such health risks arise due to direct contact with the wearer's face and the inhalation of gases, fibers, or other particles from the material(s) in the face mask. The U.S. FDA follows the International Standard ISO 10993 for determining biocompatibility of medical devices, including respirators and medical masks (FDA, 2016). Table 4 summarizes the biocompatibility rating of the materials assessed in this study. The only filter materials for which biocompatibility have been confirmed is the N95 particulate respirator and the industrial composite filter. Surprisingly, it has been demonstrated that surgical masks do not always meet the criteria for biocompatibility (Sipahl et al., 2018). 
Table 4. Construction, pressure drop, and biocompatibility of filter materials.

\begin{tabular}{lll}
\hline Filter Material & Pressure drop $\left(\mathrm{mm} \mathrm{H}_{2} \mathrm{O}\right)$ for 4.30 and $13.0 \mathrm{~cm} \mathrm{~s}^{-1}$ & Biocompatibility \\
\hline $3 \mathrm{M}$ particle respirator (N95) & $3^{\mathrm{a}}, 7^{\mathrm{a}}$ & Confirmed biocompatible \\
Allergen filter & $14^{\mathrm{a}}, 49$ & Potentially biocompatible \\
Vacuum bag & $14^{\mathrm{a}}, 42$ & Potentially biocompatible \\
Surgical mask & $7^{\mathrm{a}}, 49$ & Some confirmed biocompatible, some \\
& & confirmed incompatible \\
Bandana, 2 layers & $7^{\mathrm{a}}, 35$ & Potentially biocompatible \\
Heavy duty tool wipe & $7^{\mathrm{a}}, 42$ & Potentially biocompatible \\
Industrial composite filter & $4^{\mathrm{a}}, 40$ & Confirmed biocompatible \\
\hline
\end{tabular}

a Materials for which the pressure drop did not exceed the maximum allowed during exhalation for N95 certification (25 mm $\left.\mathrm{H}_{2} \mathrm{O}\right)(\mathrm{NIOSH}, 2015)$.

\section{CONCLUSIONS}

The filtration performance of a range of filter materials was assessed at three face velocities for the purpose of finding strong candidates for DIY face mask construction. Each material studied reduced the percentage of aerosol particles with diameters $25-500 \mathrm{~nm}$. However, only the allergen filter and the $\mathrm{N} 95$ respirator met the threshold criteria of allowing $\leq 5 \%$ of particles to penetrate at each of the three face velocities employed. The next best results were obtained for the vacuum bag and the industrial composite filter, with percent penetrations of $\leq 34 \%$ and $\leq 24 \%$ under conditions of light work, and $\leq 45 \%$ and $\leq 19 \%$ under conditions of heavy work for $25-500 \mathrm{~nm}$ aerosol particles. Notably, the vacuum bag and the industrial composite filter each outperformed the surgical mask, with penetrations of $\leq 57 \%$ under light work and $\leq 61 \%$ under heavy work for 25-500 nm aerosol particles. The double-layered bandana was the least effective filtration material.

We also report filter qualities in this study, which takes the pressure drop across each filter material into account. All materials met the minimum filter quality of $0.03 \mathrm{~mm} \mathrm{H}_{2} \mathrm{O}^{-1}$ recommended by the WHO as of June 2020 at the face velocity that corresponds with light physical work, $4.3 \mathrm{~cm} \mathrm{~s}^{-1}$. The materials with the highest filter qualities at the highest face velocity were the N95 respirator and the allergen filter, followed by the industrial composite filter for $25-500 \mathrm{~nm}$ aerosol particles, all of which exceed the minimum recommended filter quality. Lower filter qualities were observed for the vacuum bag, which failed to meet the recommended minimum filter quality for $300 \mathrm{~nm}$ aerosol particles, and the surgical mask, which only met the minimum recommended filter quality for the smallest and largest particle diameters. The lowest filter quality values at this face velocity were observed for the two-layered bandana and the heavyduty tool wipe, and neither of these materials met the recommended minimum filter quality for aerosol particles with diameters less than or equal to $300 \mathrm{~nm}$.

The effect of layering filter material between two layers of a standard cotton bandana was also determined. Decreases in the percent penetration of $100 \mathrm{~nm}$ particles were observed when the allergen filter and vacuum bag were combined with the cotton bandana $(-82 \% \pm 168 \%$ and $-7 \% \pm$ $37 \%$ respectively), but these decreases were not significant in comparison with their uncertainties. The addition of the two layers of cotton bandana to one layer of the heavy-duty tool wipe did result in a significant decrease in percent penetration of $100 \mathrm{~nm}$ aerosol particles of $-8 \% \pm 1 \%$. These results indicate that layering may decrease the percent penetration of aerosol particles through materials which perform poorly when used alone, but may not significantly enhance the protection provided by more effective filter materials. Unfortunately, improvements observed in percent penetration may be offset by increases in pressure drop due to the added layers.

According to our analysis of the filter material structure and morphology, the thicker materials and materials composed of non-woven layers were generally more effective in reducing the percent penetration of aerosol particles. These guidelines can be used for the selection of additional candidate filter materials if their structural properties are known. However, additional information in needed on structure-filter quality relationships, and the filtration efficiency of additional candidate materials should be tested prior to implementation in face masks. 
The materials that showed the most promise for DIY mask construction were two household materials (an allergen filter and a vacuum bag) and an industrial composite filter (which is available in bulk quantities) based on percent penetration, pressure drop, and filter quality. Notably, each of these outperformed surgical masks widely used by patients and medical staff. In addition, the industrial composite filter has previously been tested for biocompatibility, and is suitable for face mask materials, whereas the biocompatibility of the allergen filter and vacuum bag are unknown.

\section{ACKNOWLEDGMENTS}

We would like to acknowledge Texas A\&M University Geosciences Dean's Disciplinary/ Interdisciplinary Initiative for funding.

\section{DISCLAIMER}

Reference to any companies or specific commercial products does not constitute an endorsement of said products. The respirators, surgical mask, and candidate mask construction materials in this manuscript were evaluated for the purposes of filtration, but are not endorsed as protective measures against the transmission of SARS-CoV-2 or other infectious agents.

\section{SUPPLEMENTARY MATERIAL}

Supplementary material for this article can be found in the online version at https://doi. org/10.4209/aaqr.200633

\section{REFERENCES}

Alderman, S.L., Parsons, M.S., Hogancamp, K.U., Waggoner, C.A. (2008). Evaluation of the effect of media velocity on filter efficiency and most penetrating particle size of nuclear grade highefficiency particulate air filters. J. Occup. Environ. Hyg. 5, 713-720. https://doi.org/10.1080/1 5459620802383934

Allen, J., Marr, L. (2020). Re-thinking the potential for airborne transmission of SARS-CoV-2. Preprints 2020, 2020050126. https://doi.org/10.20944/preprints202005.0126.v1

Anderson, N.J., Cassidy, P.E., Janssen, L.L., Dengel, D.R. (2006). Peak inspiratory flows of adults exercising at light, moderate and heavy work loads. J. Int. Soc. Respir. Prot. 23, 53-63.

Bałazy, A., Toivola, M., Adhikari, A., Sivasubramani, S.K., Reponen, T., Grinshpun, S.A. (2006). Do N95 respirators provide 95\% protection level against airborne viruses, and how adequate are surgical masks? Am. J. Infect. Control 34, 51-57. https://doi.org/10.1016/j.ajic.2005.08.018

Bian, Y., Wang, S., Zhang, L., Chen, C. (2020). Influence of fiber diameter, filter thickness, and packing density on $\mathrm{PM}_{2.5}$ removal efficiency of electrospun nanofiber air filters for indoor applications. Build. Environ. 170, 106628. https://doi.org/10.1016/j.buildenv.2019.106628

Brown, R.C. (1993). Air filtration: An integrated approach to the theory and applications of fibrous filters. Pergamon.

Davies, A., Thompson, K.A., Giri, K., Kafatos, G., Walker, J., Bennett, A. (2013). Testing the efficacy of homemade masks: Would they protect in an influenza pandemic? Disaster Med. Public Health Prep. 7, 413-418. https://doi.org/10.1017/dmp.2013.43

El-Atab, N., Qaiser, N., Badghaish, H., Shaikh, S.F., Hussain, M.M. (2020). Flexible nanoporous template for the design and development of reusable anti-COVID-19 hydrophobic face masks. ACS Nano 14, 7659-7665. https://doi.org/10.1021/acsnano.0c03976

Eninger, R.M., Honda, T., Adhikari, A., Heinonen-Tanski, H., Reponen, T., Grinshpun, S.A. (2008a). Filter performance of $\mathrm{N} 99$ and $\mathrm{N} 95$ facepiece respirators against viruses and ultrafine particles. Ann. Occup. Hyg. 52, 385-396. https://doi.org/10.1093/annhyg/men019

Eninger, R.M., Honda, T., Reponen, T., McKay, R., Grinshpun, S.A. (2008b). What does respirator certification tell us about filtration of ultrafine particles? J. Occup. Environ. Hyg. 5, 286-295. https://doi.org/10.1080/15459620801960153 
European Committee for Standardization (CEN) (2009). Biological evaluation of medical devices - Part 17: Establishment of allowable limits for leachable substances. Standart No. EN ISO 10993-17, International Organization for Standardization.

Fears, A.C., Klimstra, W.B., Duprex, P., Hartman, A., Weaver, S.C., Plante, K.S., Mirchandani, D., Plante, J., Aguilar, P.V., Fernandez, D., Nalca, A., Totura, A., Dyer, D., Kearney, B., Lackemeyer, M., Bohannon, J.K., Johnson, R., Garry, R.F., Reed, D.S., Roy, C.J. (2020). Comparative dynamic aerosol efficiencies of three emergent coronaviruses and the unusual persistence of SARS-CoV-2 in aerosol suspensions. medRxiv 2020.2004.2013.20063784. https://doi.org/10.1101/2020.04.13.20063784

Food and Drug Administration (FDA) (2016). Guidance for Industry and Food and Drug Administration Staff. Use of International Standard ISO 10993-1, "Biological evaluation of medical devices - Part 1: Evaluation and testing within a risk management process". Food and Drug Administration, USA.

Han, Q., Lin, Q., Ni, Z., You, L. (2020). Uncertainties about the transmission routes of 2019 novel coronavirus. Influenza Other Respir. Viruses 14, 470-471. https://doi.org/10.1111/irv.12735

Hao, W., Parasch, A., Williams, S., Li, J., Ma, H., Burken, J., Wang, Y. (2020). Filtration performances of non-medical materials as candidates for manufacturing facemasks and respirators. Int. J. Hyg. Environ. Health 229, 113582. https://doi.org/10.1016/j.ijheh.2020.113582

He, M., Dhaniyala, S. (2013). A multiple charging correction algorithm for scanning electrical mobility spectrometer data. J. Aerosol Sci. 61, 13-26. https://doi.org/10.1016/j.jaerosci.2013. 03.007

Howard, J., Huang, A., Li, Z., Tufekci, Z., Zdimal, V., Westhuizen, H.M. van der, Delft, A. von, Price, A., Fridman, L., Tang, L.H., Tang, V., Watson, G.L., Bax, C.E., Shaikh, R., Questier, F., Hernandez, D., Chu, L.F., Ramirez, C.M., Rimoin, A.W. (2020). Face masks against COVID-19: An evidence review. Preprints https://doi.org/10.20944/preprints202004.0203.v2

Huang, S.H., Chen, C.W., Kuo, Y.M., Lai, C.Y., McKay, R., Chen, C.C. (2013). Factors affecting filter penetration and quality factor of particulate respirators. Aerosol Air Qual. Res. 13, 162-171. https://doi.org/10.4209/aaqr.2012.07.0179

Janssen, L., Anderson, N., Cassidy, P., Weber, R., Nelson, T. (2005). Interpretation of inhalation airflow measurements for respirator design and testing. J. Int. Soc. Respir. Prot. 22, 122-141. https://doi.org/10.3320/1.2753437

Jung, H., Kim, J.K., Lee, S., Lee, J., Kim, J., Tsai, P., Yoon, C. (2014). Comparison of filtration efficiency and pressure drop in anti-yellow sand masks, quarantine masks, medical masks, general masks, and handkerchiefs. Aerosol Air Qual. Res. 14, 991-1002. https://doi.org/10.42 09/aaqr.2013.06.0201

Konda, A., Prakash, A., Moss, G.A., Schmoldt, M., Grant, G.D., Guha, S. (2020). Aerosol filtration efficiency of common fabrics used in respiratory cloth masks. ACS Nano 14, 6339-6347. https://doi.org/10.1021/acsnano.0c03252

Leung, N.H.L., Chu, D.K.W., Shiu, E.Y.C., Chan, K.H., McDevitt, J.J., Hau, B.J.P., Yen, H.L., Li, Y., Ip, D.K.M., Peiris, J.S.M., Seto, W.H., Leung, G.M., Milton, D.K., Cowling, B.J. (2020). Respiratory virus shedding in exhaled breath and efficacy of face masks. Nature Med. 26, 676-680. https://doi.org/10.1038/s41591-020-0843-2

Lindsley, W.G., Blachere, F.M., Thewlis, R.E., Vishnu, A., Davis, K.A., Cao, G., Palmer, J.E., Clark, K.E., Fisher, M.A., Khakoo, R., Beezhold, D.H. (2010). Measurements of airborne influenza virus in aerosol particles from human coughs. PLoS One 5, e15100. https://doi.org/10.1371/journal. pone.0015100

Liu, Y., Ning, Z., Chen, Y., Guo, M., Liu, Y., Gali, N.K., Sun, L., Duan, Y., Cai, J., Westerdahl, D., Liu, X., Ho, K.F., Kan, H., Fu, Q., Lan, K. (2020). Aerodynamic characteristics and RNA concentration of SARS-CoV-2 aerosol in Wuhan hospitals during COVID-19 outbreak. bioRxiv 2020.2003.2008.982637. https://doi.org/10.1101/2020.03.08.982637

Lustig, S.R., Biswakarma, J.J.H., Rana, D., Tilford, S.H., Hu, W., Su, M., Rosenblatt, M.S. (2020). Effectiveness of common fabrics to block aqueous aerosols of virus-like nanoparticles. ACS Nano 14, 7651-7658. https://doi.org/10.1021/acsnano.0c03972

Macintyre, C.R., Chughtai, A.A. (2015). Facemasks for the prevention of infection in healthcare and community settings. BMJ 350, h694. https://doi.org/10.1136/bmj.h694

Morawska, L., Johnson, G.R., Ristovski, Z.D., Hargreaves, M., Mengersen, K., Corbett, S., Chao, C.Y.H., Li, Y., Katoshevski, D. (2009). Size distribution and sites of origin of droplets expelled 
from the human respiratory tract during expiratory activities. J. Aerosol. Sci. 40, 256-269. https://doi.org/10.1016/j.jaerosci.2008.11.002

National Center for Immunization and Respiratory Diseases (NCIRD) (2020). Use of cloth face coverings to help slow the spread of COVID-19. https://www.cdc.gov/coronavirus/2019ncov/prevent-getting-sick/diy-cloth-face-coverings.html?fbclid=IwAR3fnY1F69-EO-ibiv12puU L509KunxKapEpznPDOxbmxg5Gie_V36DoKE0 (accessed May 17, 2020).

National Institute for Occupational Safety and Health (NIOSH) (1995). Part II: Department Of Health And Human Services: Department Of Labor: Department Of Labor: Department Of Health And Human Services: Department Of Health And Human Services: Public Health Service: Rules and Regulations: Respiratory Protective Devices: [FR DOC \# 95-13287]. National Institute for Occupational Safety and Health, pp. 30336-30398.

National Institute for Occupational Safety and Health (NIOSH) (2019). Determination of particulate filter efficiency level for N95 series filters against solid particulates for non-powered, airpurifying respirators standard testing procedure (STP). Standard Respirator Testing Procedures Air-Purifying Respirators, NIOSH.

Oberg, T., Brosseau, L.M. (2008). Surgical mask filter and fit performance. Am. J. Infect. Control 36, 276-282. https://doi.org/10.1016/j.ajic.2007.07.008

Occupational Safety and Health Administration (OSHA) (2004). Appendix A to $\$ 1910.134-$ Fit Testing Procedures (Mandatory). Office of the Federal Register, National Archives and Records Administration, Washington DC.

Pentyala, P., Shahid, M., Ramamirtham, S., Basavaraj, M.G. (2018). Porous materials from oppositely charged nanoparticle gel emulsions. Colloids Surf., A 544, 172-178. https://doi.org/ 10.1016/j.colsurfa.2018.02.026

Ramirez, J., O'Shaughnessy, P. (2017). Filter penetration and breathing resistance evaluation of respirators and dust masks. J. Occup. Environ. Hyg. 14, 148-157. https://doi.org/10.1080/1545 9624.2016.1237027

Raynor, P.C., Leith, D., Lee, K.W., Mukund, R. (2011). Sampling and Analysis Using Filters, in: Kulkarni, P., Baron, P.A., Willeke, K. (Eds.), Aerosol Measurement, John Wiley \& Sons, Ltd, pp. 107-128. https://doi.org/10.1002/9781118001684.ch7

Rengasamy, S., Eimer, B., Shaffer, R.E. (2010). Simple respiratory protection-evaluation of the filtration performance of cloth masks and common fabric materials against $20-1000 \mathrm{~nm}$ size particles. Ann. Occup. Hyg. 54, 789-798. https://doi.org/10.1093/annhyg/meq044

Rengasamy, S., Shaffer, R., Williams, B., Smit, S. (2017). A comparison of facemask and respirator filtration test methods. J. Occup. Environ. Hyg. 14, 92-103. https://doi.org/10.1080/15459624. 2016.1225157

Sachinidou, P., Bahk, Y.K., Wang, J. (2017). An integrative model for the filtration efficiencies in realistic tests with consideration of the filtration velocity profile and challenging particle size distribution. Aerosol Sci. Technol. 51, 178-187. https://doi.org/10.1080/02786826.2016.1254 720

Schilling, K., Gentner, D., Wilen, L., Medina, A., Buehler, C., Perez-Lorenzo, L.J., Godri Pollitt, K.J., Bergemann, R., Bernardo, N., Peccia, J., Wilczynski, V., Lattanza, L. (2020). An accessible method for screening aerosol filtration identifies poor-performing commercial masks and respirators. (SSRN Scholarly Paper No. ID 3592485). Social Science Research Network, Rochester, NY. https://doi.org/10.2139/ssrn.3592485

Shakya, K.M., Noyes, A., Kallin, R., Peltier, R.E. (2017). Evaluating the efficacy of cloth facemasks in reducing particulate matter exposure. J. Exposure Sci. Environ. Epidemiol. 27, 352-357. https://doi.org/10.1038/jes.2016.42

Sipahl, H., Bayram, F.E.O., Palabiyik, S.S., Bayram, D., Aydin, A. (2018). Investigation of the biocompatibility of surgical masks. Pteridines 29, 80. https://doi.org/10.1515/pteridines-20180007

Stadnytskyi, V., Bax, C.E., Bax, A., Anfinrud, P. (2020). The airborne lifetime of small speech droplets and their potential importance in SARS-CoV-2 transmission. PNAS 117, 11875-11877. https://doi.org/10.1073/pnas.2006874117

Stevens, G.A., Moyer, E.S. (1989). "Worst case" aerosol testing parameters: I. Sodium chloride and dioctyl phthalate aerosol filter efficiency as a function of particle size and flow rate. Am. Ind. Hyg. Assoc. J. 50, 257-264. https://doi.org/10.1080/15298668991374615 
van der Sande, M., Teunis, P., Sabel, R. (2008). Professional and home-made face masks reduce exposure to respiratory infections among the general population. PLoS One 3, e2618. https://doi.org/10.1371/journal.pone.0002618

van Doremalen, N., Bushmaker, T., Morris, D.H., Holbrook, M.G., Gamble, A., Williamson, B.N., Tamin, A., Harcourt, J.L., Thornburg, N.J., Gerber, S.I., Lloyd-Smith, J.O., de Wit, E., Munster, V.J. (2020). Aerosol and surface stability of SARS-CoV-2 as compared with SARS-CoV-1. N. Engl. J. Med. 382, 1564-1567. https://doi.org/10.1056/NEJMc2004973

Wang, J., Du, G. (2020). COVID-19 may transmit through aerosol. Ir. J. Med. Sci. 189, 1143-1144. https://doi.org/10.1007/s11845-020-02218-2

Wells, W.F. (1934). On air-borne infection*: Study II. droplets and droplet nuclei. Am. J. Epidemiol. 20, 611-618. https://doi.org/10.1093/oxfordjournals.aje.a118097

Wells, W.F. (1955). Airborne contagion and air hygiene; an ecological study of droplet infections. Harvard University Press, Cambridge.

Wölfel, R., Corman, V.M., Guggemos, W., Seilmaier, M., Zange, S., Müller, M.A., Niemeyer, D., Jones, T.C., Vollmar, P., Rothe, C., Hoelscher, M., Bleicker, T., Brünink, S., Schneider, J., Ehmann, R., Zwirglmaier, K., Drosten, C., Wendtner, C. (2020). Virological assessment of hospitalized patients with COVID-2019. Nature 581, 465-469. https://doi.org/10.1038/s41586-020-2196-x

World Health Organization (WHO) (2020). Advice on the use of masks in the context of COVID19: Interim guidance, 6 April 2020. World Health Organization. https://apps.who.int/iris/handl e/10665/331693. License: CC BY-NC-SA 3.0 IGO.

World Health Organization (WHO) (2021). Weekly epidemiological update - 16 March 2021. https://www.who.int/publications/m/item/weekly-epidemiological-update---16-march-2021

Yan, J., Guha, S., Hariharan, P., Myers, M. (2019). Modeling the effectiveness of respiratory protective devices in reducing influenza outbreak. Risk Anal. 39, 647-661. https://doi.org/10.1 111/risa.13181

Yang, H., Deng, H., Zhai, L., Deng, B. (2020). PotentiaL natural fibrous filter against $\mathrm{PM}_{2.5}$ from juncus effuses. J. Nat. Fibers https://doi.org/10.1080/15440478.2020.1788481

Yuasa, H., Kumita, M., Honda, T., Kimura, K., Nozaki, K., Emi, H., Otani, Y. (2015). Breathing simulator of workers for respirator performance test. Ind. Health 53, 124-131. https://doi.org/ 10.2486/indhealth.2014-0079

Zangmeister, C.D., Radney, J.G., Vicenzi, E.P., Weaver, J.L. (2020). Filtration efficiencies of nanoscale aerosol by cloth mask materials used to slow the spread of SARS-CoV-2. ACS Nano 14, 9188-9200. https://doi.org/10.1021/acsnano.0c05025

Zhao, M., Liao, L., Xiao, W., Yu, X., Wang, H., Wang, Q., Lin, Y.L., Kilinc-Balci, F.S., Price, A., Chu, L., Chu, M.C., Chu, S., Cui, Y. (2020). Household materials selection for homemade cloth face coverings and their filtration efficiency enhancement with triboelectric charging. Nano Lett. 20, 5544-5552. https://doi.org/10.1021/acs.nanolett.0c02211

Zhu, N., Zhang, D., Wang, W., Li, X., Yang, B., Song, J., Zhao, X., Huang, B., Shi, W., Lu, R., Niu, P., Zhan, F., Ma, X., Wang, D., Xu, W., Wu, G., Gao, G.F., Tan, W. (2020). A novel coronavirus from patients with pneumonia in China, 2019. N. Engl. J. Med. 382, 727-733. https://doi.org/10.10 56/NEJMoa2001017

Zou, G., She, J., Peng, S., Yin, Q., Liu, H., Che, Y. (2020). Two-dimensional SEM image-based analysis of coal porosity and its pore structure. Int. J. Coal Sci. Technol. 7, 350-361. https://doi.org/10. 1007/s40789-020-00301-8 